\title{
Accounting for anthropic energy flux of traffic in winter urban road surface temperature simulations with the TEB model
}

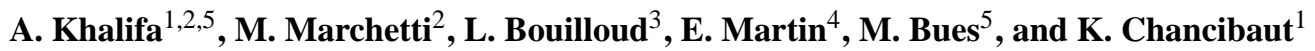 \\ ${ }^{1}$ IFSTTAR, Centre de Nantes, route de Bouaye, CS4, 44344 Bouguenais CEDEX, France \\ ${ }^{2}$ Cerema - DTer Est - LR Nancy, 71 rue de la grande haie, 54510 Tomblaine, France \\ ${ }^{3}$ Météo France, Direction de la Production, 42 avenue G. Coriolis, 31057 Toulouse CEDEX, France \\ ${ }^{4}$ CNRM-GAME (Météo-France, CNRS), Météo France, 42 avenue G. Coriolis, 31057 Toulouse CEDEX, France \\ ${ }^{5}$ Université de Lorraine, UMR 7359-GeoRessources CNRS/UL/CREGU, ENSG, \\ 54518 Vandoeuvre-lès-Nancy CEDEX, France
}

Correspondence to: A. Khalifa (abderrahmen.khalifa@gmail.com)

Received: 23 April 2015 - Published in Geosci. Model Dev. Discuss.: 22 June 2015

Revised: 26 December 2015 - Accepted: 5 January 2016 - Published: 9 February 2016

\begin{abstract}
Snowfall forecasts help winter maintenance of road networks, ensure better coordination between services, cost control, and a reduction in environmental impacts caused by an inappropriate use of de-icers. In order to determine the possible accumulation of snow on pavements, forecasting the road surface temperature (RST) is mandatory. Weather outstations are used along these networks to identify changes in pavement status, and to make forecasts by analyzing the data they provide. Physical numerical models provide such forecasts, and require an accurate description of the infrastructure along with meteorological parameters. The objective of this study was to build a reliable urban RST forecast with a detailed integration of traffic in the Town Energy Balance (TEB) numerical model for winter maintenance. The study first consisted in generating a physical and consistent description of traffic in the model with two approaches to evaluate traffic incidence on RST. Experiments were then conducted to measure the effect of traffic on RST increase with respect to non-circulated areas. These field data were then used for comparison with the forecast provided by this traffic-implemented TEB version.
\end{abstract}

\section{Introduction}

During the winter period, precipitations may accumulate on road surfaces, with special danger in the case of snow and black ice, since they reduce road grip and therefore impact the road users' safety. One of the roles of maintenance services during winter is to ensure network practicability, and in France the winter season for road services runs from 15 October one year to 15 March of the following year. Their work is grouped under the term "winter maintenance" designed to provide optimal conditions of safety and of mobility. For years, winter operations services have been aware of the environmental risks such as the extensive use of deicers on road networks. Through training and standard productions, they have begun to make infrastructure managers aware of the need to control the amounts spread. Many studies are dedicated to forecasting of the road surface temperature (RST) (Shao and Lister, 1995; Sass, 1997; Paumier and Arnal, 1998; Chapman et al., 2001; Crevier and Delage, 2001; Raatz and Niebrügge, 2002; Bouilloud and Martin, 2006; Bouilloud et al., 2010). A forecast of the snowfall and RST helps coordination of winter maintenance services, optimizing their costs, and reduces the environmental impacts caused by an inappropriate use of de-icers. Considerable effort has been devoted to meteorological forecasting of these adverse weather conditions, particularly for road freezing conditions (Rayer, 1987; Takle, 1990; Borgen et al., 1992; Saas, 1992; Brown and Murphy, 1996). To forecast RST, winter maintenance operators rely on numerical models. Improvement of these models consisted in producing a forecast for a full network by incorporating the influence of both meteorological and geographical parameters. However, traffic has so far been a challenging parameter to include in 
RST forecasts (Prusa et al., 2002). In the present study, we will be interested in taking into account the impact of traffic in modeling the RST. A short literature review of the thermal effect of the traffic will be presented to identify and to quantify these impacts. A model dedicated to an urban configuration was chosen. The heat fluxes associated with traffic were investigated in detail for their introduction into this model. The modification in the energy balance caused by the presence of vehicles was then evaluated. Compared with initial traffic implementation in the model, two different approaches were considered. The first consisted in improving the evaluation of the heat flux released by traffic. The second was based on an explicit representation of traffic within the model. Forecasts and field results will be compared and discussed.

\section{State of the art and objective of the study}

Accumulation of snow or ice on roads generates hazardous traffic conditions. Several models exist and are based on forecasts of the road surface status. The heat flux associated with passing vehicles was partially taken into account by some models (IceBreak, Shao and Lister, 1996; IceMister, Chapman et al., 2001; the energy balance model from the UK Meteorological Office with a modified radiation scheme, Jacobs and Raatz, 1996) and neglected by others (DMI-Hirlam-R, Saas, 1992; the energy balance model from the UK Meteorological Office, Rayer, 1987; ISBA-Route/CROCUS, Bouilloud and Martin, 2006; Bouilloud et al., 2010). Shao and Lister (1996) included traffic through a modification of the exchange coefficient between the road surface and the atmosphere layer above it, and a correction of the net infrared radiation the road received according to traffic density. Chapman et al. (2001) selected three traffic effects: increase in RST through a correction factor, a change in net infrared balance due to passing vehicles with a multiplication coefficient applied to the emitted radiation, and an increase in turbulent exchange by adding $2 \mathrm{~m} \mathrm{~s}^{-1}$ to the wind speed. Jacobs and Raatz (1996) considered that traffic increased turbulent exchanges, and therefore imposed a minimal wind speed of $5.14 \mathrm{~m} \mathrm{~s}^{-1}$ in daytime, and $2.57 \mathrm{~m} \mathrm{~s}^{-1}$ at night and during the holiday seasons. In such cases, only specific physical processes associated with traffic are considered as relevant, while other ones are neglected. None provided or analyzed the relative importance in terms of the energy fluxes of these processes related to the presence of vehicles.

Recently several studies have been undertaken to evaluate the thermal effects of traffic on the RST. A vehicle is a source of multiple forms of heat (Prusa et al., 2002) (Fig. 1). Indeed, we can distinguish between direct and indirect consequences due to passing vehicles on the road. Direct impacts are created by the heat flux generated by the engine and the exhaust system, the radiative flux emitted by the bottom of the vehicle and the tire frictional heat flux. Vehicles also indirectly influence the road surface energy balance by mod- ification of the radiative balance. They can block longwave radiation exchange whilst also preventing shortwave radiation from reaching the road surface during the day. Traffic motion will also cause additional mixing of air above the road surface, promoting increased turbulent flow. The bibliographic study has led to the identification of the different processes associated with traffic, and their contribution to an increase of 2 to $3{ }^{\circ} \mathrm{C}$ of RST. However, no literature data provide any quantitative evaluation of these different impacts. Prusa et al. (2002) used physical equations and thermodynamic laws to evaluate the thermal input of some of the processes associated with traffic (exhaust system, engine, friction, etc.). Their approach did not state to what extent each process contributed, nor was it validated by any experimental study. Farmer and Tonkinson (1989) showed that the general cumulative effect of these impacts on the diurnal temperature cycle is to promote warmer RST on heavily trafficked roads. As an example, in a study in the Stockholm area (Sweden), Gustavsson and Bogren (1991) showed RST differences by up to $2{ }^{\circ} \mathrm{C}$ due to the differences in traffic conditions between urban and rural areas, especially during peak hours. Surgue et al. (1983) reported that recorded RST was usually several degrees greater on roads where traffic is the heaviest. The impact of vehicles can be quantified on multilaned roads, where the increased volume of slow vehicles on nearside lanes can raise the RST by up to $2^{\circ} \mathrm{C}$ (Parmenter and Thornes, 1986). This result was confirmed by Chapman et al. (2001). They also indicated that making an accurate evaluation of the traffic heat input on RST is relatively difficult, firstly because of the plurality of the impact processes, and secondly because of the change in heat input according to these parameters (traffic density, vehicles speed, road topographic profile and atmospheric stability, etc.). Fujimoto et al. (2008) showed that the temperature in the vehiclepassage area was approximately $3^{\circ} \mathrm{C}$ above that in the nonvehicle-passage area during a sunny winter day. Furthermore, Fujimoto et al. (2010) reported that the RST under vehicles waiting at traffic signals was 3 to $4{ }^{\circ} \mathrm{C}$ higher than that nearby. Some experiments with a thermal mapping vehicle indicated that traffic has a significant effect on RST (Khalifa et al., 2014), especially in traffic light areas and/or on roads with high traffic density.

All the references quoted above are related to the winter season and show that traffic has a significant effect on the RST, especially near traffic signals and/or on roads with a high density of traffic. Our study aimed at describing this traffic effect during the winter season on the pavement energy balance. This involved integrating a theoretical traffic description into the TEB numerical model dedicated to an urban configuration, and then quantifying how much the traffic energy input affects the RST both on the basis of field experimental measurements (weather, traffic) and numerical experiments. 


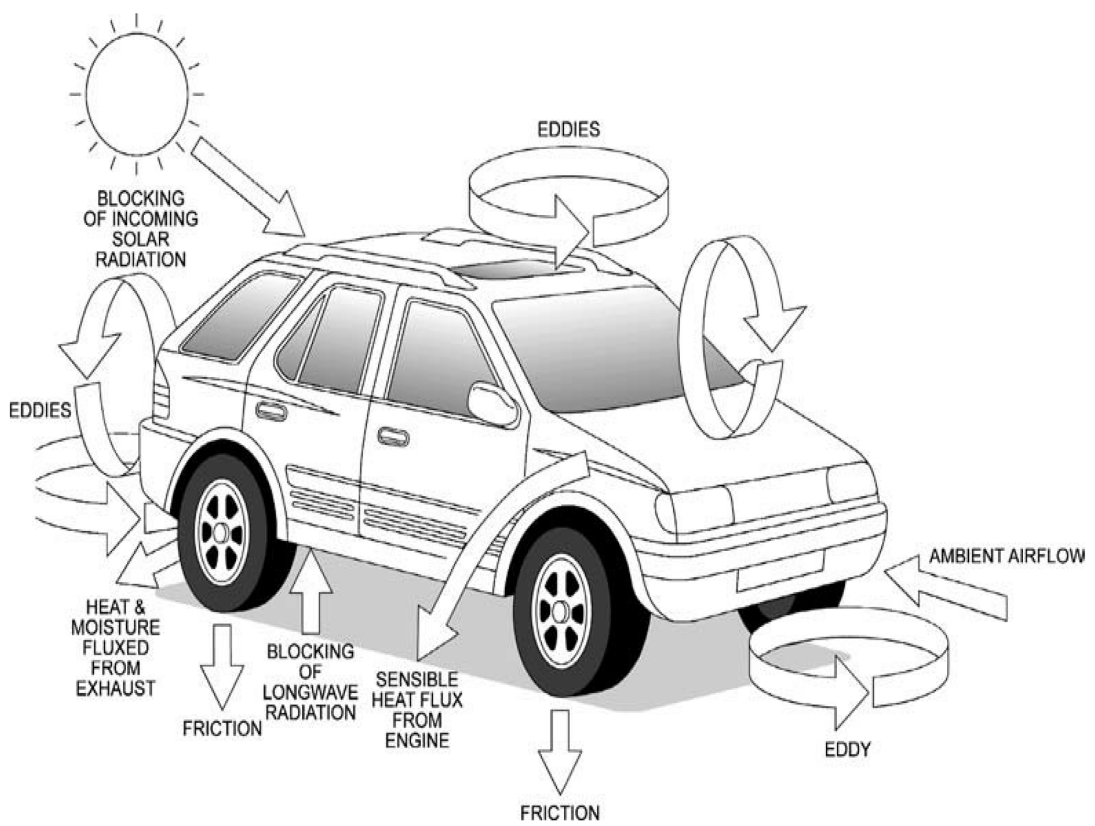

Figure 1. Schematic illustration of the impact of traffic on road surface temperature (adapted from Prusa et al., 2002).

\section{The Town Energy Balance model and the introduction of the fluxes associated with the traffic}

\subsection{The Town Energy Balance model}

The Town Energy Balance (TEB) model aims to parametrize the interactions between the town and the urban atmospheric canopy, and is valid for a grid mesh larger than a few hundred meters. It is based on the canyon hypothesis (Masson, 2000; Lemonsu et al., 2012; Masson et al., 2013). Previous work was performed to use the TEB in a specific winter context (Pigeon et al., 2008), with a simple description of the traffic effect on the street atmosphere: the corresponding heat flux is added as a source term in the urban canyon. In the study presented here, an analysis is conducted of the possible ways of taking into account traffic impact in modeling the RST in the winter season on the basis of Prusa and Fujimoto's approaches (Prusa et al., 2002; Fujimoto et al., 2006, 2007, 2012). That of Prusa et al. (2002) involved incorporating a global energy source representative of the traffic heat input. The approach by Fujimoto et al. $(2006,2007,2012)$ is based on an explicit representation of the different physical processes related to traffic.

The physical processes involved in modeling the road surface energy balance by the TEB model are summarized in Fig. 2. In this configuration, the road surface energy balance is expressed by the following equation:

$(\rho c)_{\text {road }} \frac{\partial \mathrm{RST}}{\partial t} \Delta Z_{\mathrm{s}}=R_{\mathrm{n}}+S_{\mathrm{a}}+L+G$.

$\Delta Z_{\mathrm{s}}$ is the thickness of the first layer of the road surface, $(\rho c)_{\text {road }}$ is the volumetric heat capacity of the road surface layer $\left(\mathrm{J} \mathrm{m}^{-3} \mathrm{~K}^{-1}\right), t$ is the time (s), $G$ is the conductive heat flux across the bottom of the road surface layer (road surface heat flux, $\left.\mathrm{W} \mathrm{m}^{-2}\right), R_{\mathrm{n}}$ is the net radiation flux ( $\left.\mathrm{W} \mathrm{m}^{-2}\right), S_{\mathrm{a}}$ is the sensible heat flux associated with natural wind $\left(\mathrm{W} \mathrm{m}^{-2}\right)$ and $L$ is the latent heat flux associated with phase transition of water (liquid-vapor, and liquid-solid) $\left(\mathrm{W} \mathrm{m}^{-2}\right)$. We chose a very low thickness value $\left(\Delta Z_{\mathrm{s}}\right.$ equal to $\left.0.001 \mathrm{~m}\right)$ so that its temperature reflects the RST. This gives a quick response of the road surface temperature to heat flux changes without thermal inertia.

Figure 2 also shows the radiative interaction coefficients $\mathrm{LW}_{x_{-} \text {to } \_} y$ between the various components $x$ and $y$ (sun, road, walls, garden, snow) of the urban canyon. The urban canyon interacts with the road surface, and the interactions are represented by the coefficients $\left(\mathrm{LW}_{x_{-} \text {to }}{ }_{\mathrm{C}}\right)$, as specified by Masson (2000). $\mathrm{LW}_{\text {Road_to_Sun }}$ is the interaction radiative coefficient between road and sun, $L_{\text {Road_to_Road }}$ is that between road and road, $L_{\text {Snow_to_Road }}$ between the snow layer and the road, $\mathrm{LW}_{\text {Walls_to_Road }}$ between walls and road and $\mathrm{LW}_{\text {Garden_to Road }}$ between garden and road. $\sigma$ is the Stefan-Boltzmann constant $\left(5.67 \times 10^{-8} \mathrm{~W} \mathrm{~m}^{-2} \mathrm{~K}^{-4}\right)$, $\varepsilon_{\text {road }}, \varepsilon_{\text {wall }}, \varepsilon_{\text {snow }}$ and $\varepsilon_{\text {garden }}$ are, respectively, the emissivity of the road (0.95), walls (0.90), snow layer (1) and garden (0.98). $\mathrm{SVF}_{\text {road }}$ and $\mathrm{SVF}_{\text {walls }}$ are, respectively, the sky view factors of the road and walls. These sky view factors are calculated by the TEB model on the basis of building height and on the road width of the urban canyon.

Among the interaction coefficients mentioned above, the one between snow and road occurs only in the presence of snow on the road. However, at this stage, the road surface was considered cleared of snow. Therefore this coefficient 


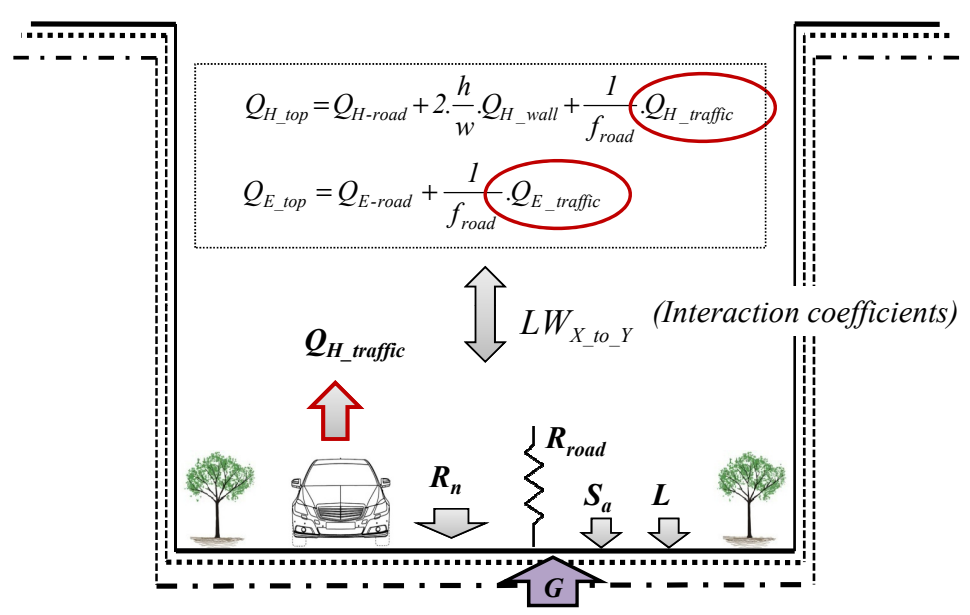

Figure 2. Different physical processes involved in the calculation of road surface energy balance in the initial TEB model configuration.

will not be taken into account in the following calculation. The interaction coefficients involved in the calculation of net radiation at the road surface are described by the following equation.

$R_{\mathrm{n}}=R_{\mathrm{nl}}+R_{\mathrm{ns}}$

$R_{\mathrm{nl}}=R_{\mathrm{ld}}+R_{\mathrm{lu}}$

$R_{\mathrm{ns}}=R_{\mathrm{sd}}+R_{\mathrm{su}}$

$R_{\mathrm{nl}}\left(\mathrm{W} \mathrm{m}^{-2}\right)$ and $R_{\mathrm{ns}}\left(\mathrm{W} \mathrm{m}^{-2}\right)$ are, respectively, the net of longwave and shortwave radiation received by the road surface. $R_{\mathrm{ld}}\left(\mathrm{W} \mathrm{m}^{-2}\right)$ is the downward longwave radiation, $R_{\mathrm{lu}}$ $\left(\mathrm{W} \mathrm{m}^{-2}\right)$ is the longwave upward radiation, $R_{\mathrm{sd}}\left(\mathrm{W} \mathrm{m}^{-2}\right)$ is the downward shortwave radiation and $R_{\mathrm{su}}\left(\mathrm{W} \mathrm{m}^{-2}\right)$ is the upward shortwave radiation.

Figure 2 also shows the aerodynamic resistance of the road $R_{\text {road }}$, used in the calculation of the turbulent sensible and latent heat fluxes $S_{\mathrm{a}}\left(\mathrm{W} \mathrm{m}^{-2}\right)$ and $L\left(\mathrm{~W} \mathrm{~m}^{-2}\right)$, respectively, defined in the TEB model by the following equations.

$$
\begin{aligned}
& S_{\mathrm{a}}=\frac{\rho_{\text {air }} c_{p}}{R_{\text {road }}}\left(\mathrm{RST}-T_{\text {lowcan }}\right) \\
&=\rho_{\text {air }} \mathrm{AC}_{\text {road }}\left(\mathrm{RST}-T_{\text {lowcan }}\right) \\
& L=\frac{\rho_{\text {air }} L_{\mathrm{v}}}{R_{\text {road-watt }}}\left(Q_{\text {sat_road }}-Q_{\text {canyon }}\right) \\
&=\rho_{\text {air }} \mathrm{AC} \text { road-watt } \\
&
\end{aligned}
$$

$c_{p}$ is the specific heat capacity $\left(\mathrm{J} \mathrm{kg}^{-1} \mathrm{~K}^{-1}\right), \rho_{\text {air }}$ is the air density $\left(\mathrm{kg} \mathrm{m}^{-3}\right)$, RST the road surface temperature $(\mathrm{K})$, and $T_{\text {lowcan }}$ is the temperature of the lower limit layer of the urban canyon $(\mathrm{K})$, and thus corresponds to the air temperature at a high of $2 \mathrm{~m} . L_{\mathrm{v}}$ is the latent heat of liquid water evaporation $\left(\mathrm{J} \mathrm{kg}^{-1}\right), Q_{\text {sat_road }}$ is the specific humidity in the road surface $\left(\mathrm{g} \mathrm{kg}^{-1}\right), Q_{\text {canyon }}$ is the specific air humidity $\left(\mathrm{g} \mathrm{kg}^{-1}\right), R_{\text {road }}$ is the aerodynamic resistance of a dry road, $R_{\text {road_wat }}$ is the aerodynamic resistance of a wet road, and $\mathrm{AC}_{\text {road }}, \mathrm{AC}_{\text {road_wat }}$ are the aerodynamic conductance for dry and wet roads, respectively.

The conduction heat flow $(G)$ between the first two road surface layers is calculated through the following equation using RST (first layer) and $\mathrm{RST}_{2}$, the temperature of the second layer; $\lambda_{1}\left(\mathrm{~W} \mathrm{~m}^{-1} \mathrm{~K}^{-1}\right)$ is the thermal conductivity of the first road layer, RST its temperature (K), $\mathrm{RST}_{2}$ the temperature of the second road layer $(\mathrm{K}), d_{1}$ the thickness of the first road layer $\left(0.001 \mathrm{~m}\right.$, as mentioned above) and $d_{2}$ that of the second road layer $(0.01 \mathrm{~m})$.

In this configuration of TEB, the traffic heat flux is involved in the calculation of the sensible $Q_{\mathrm{H}_{2} \mathrm{TOP}}\left(\mathrm{W} \mathrm{m}^{-2}\right)$ and latent turbulent heat flux $Q_{\mathrm{E} \_\mathrm{TOP}}\left(\mathrm{W} \mathrm{m}^{-2}\right)$ of the urban canyon. They are, respectively, represented by the following equations:

$$
\begin{aligned}
Q_{\text {H_TOP }} & =Q_{\text {H-ROAD }}+2 \frac{h}{w} Q_{\text {H-WALL }} \\
& +\frac{1}{f_{\text {road }}} Q_{\text {H-TRAFFIC }}, \\
Q_{\text {E_TOP }} & =Q_{\text {E-ROAD }}+\frac{1}{f_{\text {road }}} Q_{\text {E-TRAFFIC }} .
\end{aligned}
$$

$Q_{\text {H_TOP }}$ and $Q_{\text {E_tOP }}$ represent the fluxes at a high $2 \mathrm{~m}$ above the urban canyon. $h$ is the representative height building of the urban canyon in the TEB model $(\mathrm{m}) ; w$ is its width $(\mathrm{m}) .1 / f_{\text {road }}$ represents the fraction of the road relative to the width of the urban canyon. $Q_{\mathrm{H}_{-} \text {TRAFFIC }}$ and $Q_{\text {E_TRAFFIC }}$ represent the sensible and latent heat generated by traffic $\left(\mathrm{W} \mathrm{m}^{-2}\right)$, respectively. The values that were assigned to these two parameters are $Q_{\text {E_traffic }}=0 \mathrm{~W} \mathrm{~m}^{-2}$ and $Q_{\mathrm{H} \_ \text {traffic }}=20 \mathrm{~W} \mathrm{~m}^{-2}$, based on Pigeon et al. analysis of traffic inputs (Pigeon et al., 2007, 2008). These fluxes follow a simple diurnal cycle (zero at nighttime and equal to the prescribed values at daytime). The urban canyon interacts with the road surface, and the interactions are represented by the coefficients $\left(\mathrm{LW}_{x_{-} \text {to_ }}\right)$ quoted previously. 
Table 1. Dimensions of the vehicle impact zone.

\begin{tabular}{lll}
\hline Item & Symbol & Value \\
\hline Road width & $W_{\text {road }}$ & $10 \mathrm{~m}$ \\
Vehicle length & $L_{\mathrm{veh}}$ & $4.5 \mathrm{~m}$ \\
Vehicle width & $W_{\mathrm{veh}}$ & $1.5 \mathrm{~m}$ \\
Length of the impact area of the engine & $L_{\mathrm{m}}$ & $0.25 L_{\mathrm{veh}}$ \\
Width of the impact area of the engine & $W_{\mathrm{m}}$ & $0.8 \mathrm{~m}$ \\
Length of the impact area of the tires & $L_{\mathrm{p}}$ & $L_{\mathrm{veh}}$ \\
Width of the impact area of the tires & $W_{\mathrm{p}}$ & $0.12 W_{\mathrm{veh}}$ \\
Radius of the impact area of the exhaust system & $R_{\mathrm{ex}}$ & $0.40 W_{\mathrm{veh}}$ \\
\hline
\end{tabular}

The bibliographic quoted above in the state of the art section indicates that traffic has a significant effect on RST. Our interest is then to integrate traffic parameters in modeling the road surface energy balance and to evaluate the effects of these energy inputs of traffic on the RST. To do so, two approaches were then considered.

\subsection{Improving the evaluation of the heat flux released by the traffic (first approach)}

The first approach is based on a study conducted by Pigeon et al. (2008). The influence of the traffic is represented by the traffic sensible and latent heat fluxes $\left(Q_{\mathrm{H} \_ \text {traffic }}\right.$ and $Q_{\text {E_traffic }}$ in Fig. 2). In this study, a constant flow was considered and was added to the turbulent heat flux of the urban canyon. This configuration was not adapted to a specific RST forecast. The traffic energy input is not only involved in calculating the total heat flux generated by the urban canyon, but it also affects the road energy balance. Furthermore, this heat input is not constant and depends on the traffic characteristics (volume, vehicle velocity and the daily distribution density).

The improvement provided by this first approach is to consider the traffic heat input variability with respect to urban traffic characteristics (volume, vehicle velocity and density). The greater the traffic, the lower the speed, and the larger its energy input. Therefore, the heat flux generated by the traffic would no longer be considered as a constant throughout the whole period of the simulation. In addition, this approach allows us to test the TEB model sensitivity to the variation of the traffic heat inputs.

The energy provided by traffic has been studied by several authors (Klysik, 1996; Ichinose et al., 1999; Sailor and Lu, 2004; Pigeon et al., 2007, 2008; Colombert, 2008). The global heat flux generated by a vehicle, named $Q_{\mathrm{v}}$, can be expressed as a function of the net heat combustion (NHC), the fuel density $\varrho_{\text {fuel }}$ and its average consumption FE as follows:

$Q_{\mathrm{v}}=\frac{\mathrm{NHC} \rho_{\text {fuel }}}{\mathrm{FE}}$.

According to Guibet (Guibet, 1998), the NHC $\left(\mathrm{J} \mathrm{kg}^{-1}\right)$ is equal to 42700 for gasoline and 42600 for diesel. The fuel density $\varrho_{\text {fuel }}\left(\mathrm{kg} \mathrm{L}^{-1}\right)$ is equal to 0.775 for gasoline and 0.845 for diesel. The average fuel consumption FE $\left(\mathrm{km} \mathrm{L}^{-1}\right)$ de- pends on the type of fuel and on the type of traffic. In the study made by Colombert (Colombert, 2008), FE is on the order of $8.5 \mathrm{~km} \mathrm{~L}^{-1}$ (this includes among other things over-

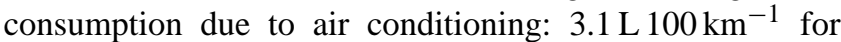

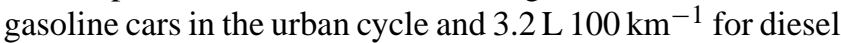
ones). According to the values from the literature (Sailor and Lu, 2004; Pigeon et al., 2007; Colombert, 2008), an average $Q_{\mathrm{v}}$ value of $3903 \mathrm{~J}$ per vehicle travel distance was selected, which corresponds to an energy per second for a given average vehicle speed. Based on the formula defined by Sailor and Lu (2004), the instantaneous flux of heat generated by traffic can be evaluated by the following equation:

$Q_{\text {traffic }}(t)=\frac{1}{S_{\text {impact }}} \frac{1}{V_{\mathrm{veh}}} D_{\mathrm{veh}}(t) Q_{\mathrm{v}}$.

$D_{\text {Veh }}$ is the traffic density (vehicles s ${ }^{-1}$ ), $V_{\text {veh }}$ is the vehicle velocity $\left(\mathrm{m} \mathrm{s}^{-1}\right)$, and $S_{\text {impact }}$ is the traffic area impact. In this configuration, $S_{\text {impact }}$ will be considered as being equal to the width of the street canyon $\left(S_{\text {impct }}=W_{\text {canyon }}\right) . Q_{\mathrm{v}}$ is the global heat flux from a vehicle $\left(\mathrm{J} \mathrm{s}^{-1}\right)$. Based on Eq. (10) and considering traffic data in a given street in Nancy (France), where the study was conducted, the traffic heat contribution $Q_{\text {traffic }}$ to the energy balance varies with time. It increases with the traffic volume and is low during off-peak hours when traffic density is low. This is illustrated in Fig. 3. To introduce the energy provided by the traffic in the TEB model, we should distinguish between the sensible and latent heats. Based on the estimation from Pigeon et al. (2007), $Q_{\text {traffic }}$ was then partitioned into sensible and latent heats, respectively represented by the following equations:

$Q_{\text {H-traffic }}(t)=0.92 Q_{\text {traffic }}(t)$,
$Q_{\text {E-traffic }}(t)=0.08 Q_{\text {traffic }}(t)$.

\subsection{Explicit representation of traffic into the model (second approach)}

This approach is based on a detailed study of the various processes of traffic impacts, and a parameterization of their physical equations was performed. The tire friction heat $S_{\mathrm{t}}$ in an extended temperature range, the shield effect on radiative flux received by the road surface from the environment and the radiative flux from the vehicle $\left(R_{\mathrm{V}}, F_{\mathrm{IR} \text { _veh_inf }}, F_{\mathrm{IR} \text { _veh_sup }}\right)$, the turbulent flux generated by passing vehicles, the sensible and latent heats released by the engine and exhaust system $\left(S_{\mathrm{m}}, E_{\mathrm{ex}}\right)$ and the aerodynamic drag associated with the vehicle's movement were selected. These impacts have been examined in many research papers by many authors. Some effects were studied by Chapman et al. (2001) and Jacobs and Raatz (1996), and mentioned previously. A detailed description of physical processes associated with traffic is provided by Prusa et al. (2002), which included friction from tires, forced convection on the road surface and the surrounding atmosphere, a modification of the radiation budget on the road owing to the presence of vehicles, and the emission 


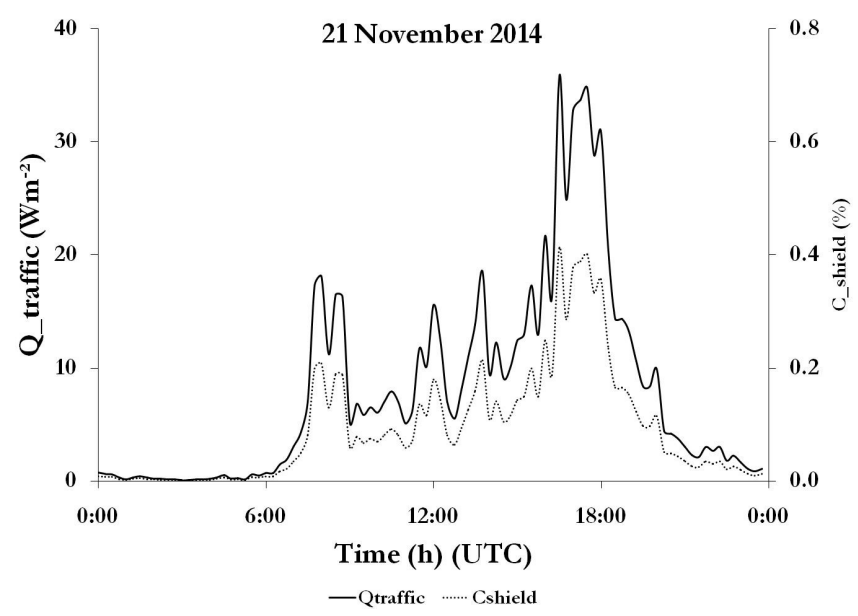

Figure 3. Hourly variations of thermal traffic contributions, and variations of the shield effect coefficient (rue Charles III, Nancy, France) for the first experiment.

of longwave radiation by their lower parts. Fujimoto et al. (2006, 2007, 2008, 2010, 2012) gave an extended description of RST changes due to tire friction, with a heat transfer coefficient as a function of the vehicle speed, and tire temperature experimentally identified as dependent on air temperature and vehicle speed, along with the heat from the lower parts of vehicles, and the heat and moisture heats from the exhaust systems. The turbulent sensible heat was also investigated (Sato et al., 2004) with a heat transfer coefficient dependent on vehicle speed. The radiative fluxes emitted by the upper and lower parts of vehicles were also specifically considered by Ishikawa et al. (1999) and Takahashi et al. (2005), and were based on the Stefan-Boltzmann law. A presentation of modified equations to take into account these processes in the TEB model was made and fully described in a previous paper (Khalifa et al., 2014), and illustrated in Fig. 4a. The heat fluxes generated by the traffic vary considerably depending on the traffic conditions (traffic congestion, fluid circulation, urban context or highway, etc.) and traffic parameters (velocity, density, volume). Furthermore, shielding due to vehicles on the road and the impact zone of their associated physical processes is partial. Khalifa et al. (2014) have identified an impact factor for each traffic physical process to evaluate its contribution, as indicated in Fig. $4 \mathrm{~b}$ and Tables 1 and 2.

In the following paragraphs, we have attempted to summarize the different approaches found in the literature and that have been analyzed in order to identify and to evaluate the different thermal traffic processes. Once the physical phenomena have been identified, a choice was made on the equations used to describe them and their adaptation for their integration into the TEB model.
Table 2. Weighting of traffic area impact zones (Khalifa et al., 2014).

\begin{tabular}{lrr}
\hline Item & Impact area $\left(\mathrm{m}^{2}\right)$ & Contribution $(\%)$ \\
\hline Engine & 2.025 & 0.25 \\
Exhaust system & 1.765 & 0.21 \\
Tires & 1.800 & 0.22 \\
Body & 2.510 & 0.32 \\
\hline
\end{tabular}

According to Fujimoto et al. (2006), the tire frictional heat flux St $\left(\mathrm{W} \mathrm{m}^{-2}\right)$ due to tire friction can be evaluated with Newton's law of cooling as follows:

$S_{\mathrm{t}} \cong \alpha_{\mathrm{tp}}\left(T_{\mathrm{t}}-\mathrm{RST}\right)$.

This equation is valid for an extended temperature range (Fujimoto et al., 2010). $\alpha_{\mathrm{tp}}$ is the heat transfer coefficient between the tire and the road surface $\left(\mathrm{W} \mathrm{m}^{-2} \mathrm{~K}^{-1}\right), T_{\mathrm{t}}$ is the tire temperature $(\mathrm{K})$ and RST the road surface temperature $(\mathrm{K})$ as mentioned above. Fujimoto et al. (2006) showed that the tire temperature depends on the ambient air temperature and the vehicle velocity. For a velocity lower than $70 \mathrm{~km} \mathrm{~h}^{-1}$, the tire temperature is expressed by the following equation:

$T_{\mathrm{t}} \cong 0.9\left(T_{\text {air }}-273.16\right)+0.33 V_{\text {veh }}+273.16$.

$T_{\text {air }}$ is the ambient air temperature $(\mathrm{K})$ and $V_{\text {veh }}$ is the vehicle velocity $\left(\mathrm{km} \mathrm{h}^{-1}\right)$. The heat transfer coefficient $\alpha_{\mathrm{tp}}$ between the tire and the road surface $\left(\mathrm{W} \mathrm{m}^{-2} \mathrm{~K}^{-1}\right)$ is determined by Browne et al. (1980) and is defined by the following relationship:

$\alpha_{\mathrm{tp}} \cong 5.9+3.7 V_{\text {veh }}$.

Vehicle-induced turbulence may also be an important factor in modifying the energy exchange between the air and the road surface in urban areas, especially under conditions of low wind speeds that are typical for the urban canyon. The turbulence generated by passing vehicles promotes forced convection between the road surface and the surrounding atmosphere. This physical process has been studied by several authors (Prusa et al., 2002; Sato et al., 2004; Fujimoto et al., 2012). Fujimoto et al. (2012) have defined an approach to assess the vehicle sensible heat flux $S_{\mathrm{va}}\left(\mathrm{W} \mathrm{m}^{-2}\right)$ due to vehicle-induced turbulence, removing energy from the pavement for a transfer to the urban canyon. Their approach consisted in defining a heat transfer coefficient $\alpha_{\mathrm{S}}\left(\mathrm{W} \mathrm{m}^{-2} \mathrm{~K}^{-1}\right.$ ) between the road surface and the surrounding atmosphere, depending on the vehicle's velocity.

$S_{\mathrm{va}} \cong \alpha_{\mathrm{s}}\left(T_{\text {air }}-\mathrm{RST}\right)$

$\alpha_{\mathrm{s}}$ is estimated from the natural wind velocity $V_{\mathrm{w}}\left(\mathrm{m} \mathrm{s}^{-1}\right)$ using the following equation:

$\alpha_{\mathrm{s}} \cong 10.4 V_{\mathrm{w}}^{0.7}+2.2$. 

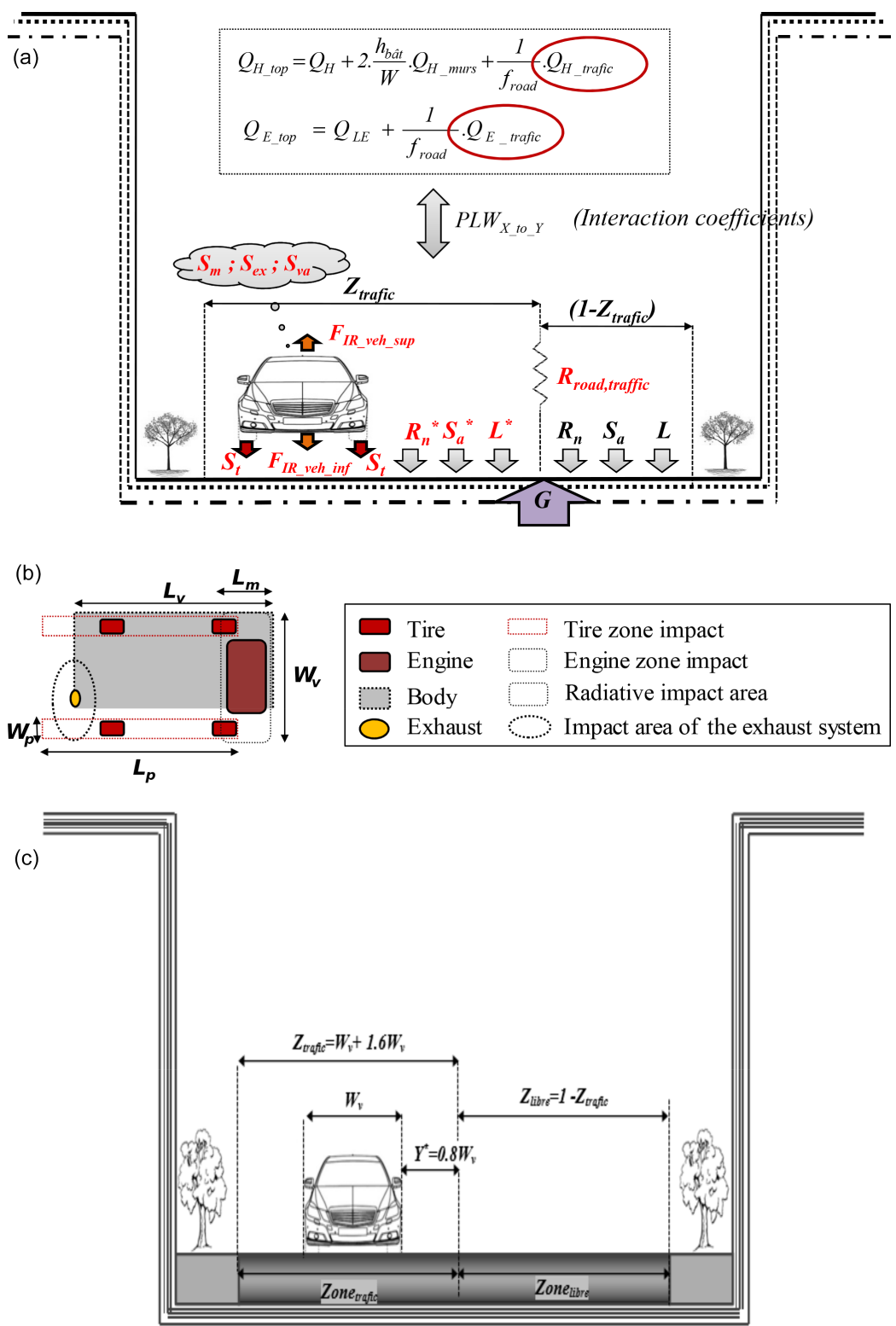

Figure 4. TEB configuration with traffic integration (a), its impact zones of the different processes (b) and the limits of the traffic impact zone (c).

The radiative heat flux $R_{\mathrm{v}}\left(\mathrm{W} \mathrm{m}^{-2}\right)$ emitted downward from the bottom of a vehicle has been studied by several authors (Ishikawa et al., 1999; Prusa et al., 2002; Takahashi et al., 2005; Fujimoto et al., 2007). These studies reported that radiant heat from the bottom of a vehicle significantly affects the heat balance on a road surface, and may be evaluated by the Stefan-Boltzmann law:

$R_{\mathrm{v}} \cong \epsilon_{\mathrm{veh}} \sigma T_{\mathrm{veh}}^{4}$.

$\epsilon_{\mathrm{veh}}$ is the vehicle emissivity, $\sigma$ the Stefan-Boltzmann constant, and $T_{\mathrm{veh}}$ is the vehicle temperature. In order to make calculation easier, the heterogeneity of materials constituting the vehicle bottom surface was ignored and an av- erage value was therefore chosen $\left(\epsilon_{\mathrm{veh}}=0.95\right)$. In this study, the vehicle will be represented by two temperatures. One is representative of the lower part, $T_{\mathrm{veh} \_ \text {inf }}(\mathrm{K})$, and another the upper part, $T_{\text {veh_sup }}(\mathrm{K}) . T_{\text {veh_inf }}$ can be evaluated within the context of the study by Fujimoto et al. (2006).

$$
\begin{aligned}
T_{\text {veh_inf }} \cong & {\left[0.2\left(T_{\text {air }}+44\right)\right.} \\
& \left.+0.2\left(T_{\text {air }}+25.9\right)+0.2\left(T_{\text {air }}+20.3\right)\right]
\end{aligned}
$$

It is assumed that the upper part of the circulating vehicle body is in thermal equilibrium with air. Then, $T_{\text {veh_sup }}$ is assumed to be equal to the ambient air temperature $(\mathrm{K})$. 
$T_{\text {veh_sup }} \cong T_{\text {air }}$

The infrared radiative flux emitted by the lower $\left(F_{\mathrm{IR}_{-} \text {veh_inf }}\right)$ and upper $\left(F_{\mathrm{IR} \_ \text {veh_sup }}\right)$ parts of the vehicle is thus evaluated in the following way:

$$
\begin{aligned}
& F_{\mathrm{IR}_{\_} \text {veh_inf }} \cong \epsilon_{\mathrm{veh}} \sigma\left[0.2\left(T_{\text {air }}+44\right)^{4}\right. \\
&\left.+0.2\left(T_{\text {air }}+25.9\right)^{4}+0.2\left(T_{\text {air }}+20.3\right)^{4}\right], \\
& F_{\mathrm{IR}_{\text {_veh_sup }}} \cong \epsilon_{\mathrm{veh}} \sigma T_{\text {air }}^{4} .
\end{aligned}
$$

Fuel consumed by the vehicle is transformed into different types of energy necessary to operate the vehicle. Most is transformed into kinetic energy for the vehicle to run and electrical energy for the battery and all the electric components of the vehicle. The other portion of energy produced by vehicle is transformed into heat flux generated by the engine and the exhaust system. Based on physical approaches and thermodynamic laws, Prusa et al. (2002) assessed the heat flow generated by the engine $S_{\mathrm{m}}\left(\mathrm{W} \mathrm{m}^{-2}\right)$ and exhaust system $E_{\mathrm{ex}}\left(\mathrm{W} \mathrm{m}^{-2}\right)$, explained by the following equations:

$E_{\mathrm{ex}} \cong m_{\mathrm{ex}} C_{\mathrm{ex}}\left(T_{\mathrm{ex}}-T_{\mathrm{air}}\right)$,

$S_{\mathrm{m}} \cong \alpha_{\mathrm{comb}} m_{\mathrm{H}_{2} \mathrm{O}} m_{\mathrm{ex}} \lambda_{\mathrm{fg}}$.

The parameters of these equations depend on the traffic conditions. $E_{\mathrm{ex}}\left(\mathrm{W} \mathrm{m}^{-2}\right)$ and $S_{\mathrm{m}}\left(\mathrm{W} \mathrm{m}^{-2}\right)$, respectively, are the exhaust and engine sensible heats, $T_{\mathrm{ex}}$ is the exhaust system exit temperature $(\mathrm{K})$ with a selected value of $350 \mathrm{~K}, m_{\mathrm{ex}}$ is the combustion products mass flow rate considered as constant and equal to $0.0323 \mathrm{~kg} \mathrm{~s}^{-1}$, and $C_{\mathrm{ex}}$ is the specific heat of the combustion products $\left(1.16 \mathrm{~kJ} \mathrm{~kg}^{-1} \mathrm{~K}^{-1}\right) . m_{\mathrm{H}_{2} \mathrm{O}}$ is the water vapor mass fraction in the exhaust system considered as constant and whose chosen value is $0.089, \alpha_{\text {comb }}$ is the fraction of water vapor that condenses, and $\lambda_{\mathrm{fg}}$ is the latent heat of condensation of water vapor (equal to $2.50 \mathrm{MJ} \mathrm{kg}^{-1}$ ). Maximum effects are achieved with $\alpha_{\mathrm{comb}}=1$. All values indicated above were given in the article by Prusa et al. (2002).

Traffic also impacts the energy balance by an intermittent interruption of the radiative flux towards the surface of the road. This phenomenon is called vehicle shield and depends on the traffic parameters. Vehicle shield firstly prevents the incident solar radiation from reaching the surface of the road. It consequently leads to a loss of energy on the surface energy balance, and secondly it blocks the radiation emitted by the road surface. This physical traffic process can be evaluated by a shield effect coefficient $C_{\text {shield }}$ (dimensionless number). The vehicle shield effect on the road has been investigated by Khalifa et al. (2014) and can be defined by the following expression:

$C_{\text {shield }} \cong \frac{T_{\text {veh }}}{t_{\text {time }}} D_{\text {traffic }}$ $t_{\text {time }}$ is the modeling time step (s), $D_{\text {traffic }}$ represents the traffic density (dimensionless number) and $T_{\mathrm{veh}}$ is the shielding time caused by the passage of one vehicle (s), equal to the ratio between the length and the vehicle velocity.

Traffic influences the heat transfer between the road surface and the surrounding atmosphere by increasing the aerodynamic resistance of air. This process has been studied by several authors and different approaches were used to evaluate it (Jacobs and Raatz, 1996; Chapman et al., 2001; Prusa et al., 2002; Sundvor, 2012). Here we will use that of Sundvor (2012) illustrated by the following equations:

$\mathrm{AC}_{\text {road }}^{*} \cong \mathrm{AC}_{\text {road }}+C_{\text {shield }} \mathrm{AC}_{\text {traffic }}$,

$\mathrm{AC}_{\text {road_watt }}^{*} \cong \mathrm{AC}_{\text {road_watt }}+C_{\text {shield }} \mathrm{AC}_{\text {traffic }}$.

$\mathrm{AC}_{\text {road }}^{*}$ and $\mathrm{AC}_{\text {road_watt }}^{*}$, respectively, are the aerodynamic conductance of a dry and a wet circulated road. They are computed with those of a non-circulated road, $\mathrm{AC}_{\text {road }}$ and $\mathrm{AC}_{\text {road_watt }}$, and the aerodynamic conductance specific to traffic $\mathrm{AC}_{\text {traffic }}=10^{-3}$ experimentally determined by Sundvor (2012) and validated with the NORTRIP model.

The incidence of traffic in shortwave radiation will be calculated as follows:

$R_{\mathrm{ns}}^{*} \cong R_{\mathrm{sd}}^{*}+R_{\mathrm{su}}^{*}$,

$R_{\text {sd }}^{*} \cong\left(1-C_{\text {shield }}\right) R_{\text {sd }}+C_{\text {shield }} a_{\text {veh_sup }} R_{\text {sd }}$,

$R_{\mathrm{su}}^{*} \cong\left(1-C_{\text {shield }}\right) R_{\text {su }}+C_{\text {shield }} a_{\text {veh_inf }} R_{\text {su }}$.

$a_{\text {veh_sup }}$ is the albedo of the upper part of vehicle, it depends on the color of its paint and an average value was chosen as equal to 0.75 (dimensionless); $a_{\mathrm{veh} \_ \text {inf }}$ is one of the lower parts of vehicles. The heterogeneity of the lower parts of vehicle bodies is neglected and an average value of 0.057 was selected (average between that of steel (0.075) and aluminum (0.039)).

The energy absorbed by vehicles constituting the traffic is incorporated into the road as a first approximation. This hypothesis is consistent with winter conditions when shortwave and longwave radiation flux are small enough, and with a traffic density profile similar to the ones used in this work. This assumption presents some limits for very heavy traffic or bolted situations $\left(C_{\text {shield }} \simeq 1\right)$ and for forecasts over large periods because of the risk of the accumulation of this vehicle-absorbed energy into the pavement. The application to another urban site will be possible on available traffic data, or considering a generic traffic density profile representative of the site. In the case of an entire city, considering the canyon hypothesis, an average traffic density could be selected, and the chosen parameterization applied, though a partition of the local climate zone will be necessary.

The other parameters chosen for the description are the road width $W_{\text {road }}$, the vehicle length $L_{\text {veh }}$, and width $W_{\text {veh }}$, those of the impact area of the engine, respectively, $L_{\mathrm{m}}$ and 
$W_{\mathrm{m}}$, those of the impact area of the tires, respectively, $L_{\mathrm{p}}$ and $W_{\mathrm{p}}$, and the radius of the impact area of the exhaust system $R_{\mathrm{ex}}$. Based on traffic data from rue Charles III (Nancy, France), the magnitude of the corresponding shield effect coefficient $C_{\text {shield }}$ on the radiative flux of the road surface is shown in Fig. 3.

This second approach of integrating traffic into the TEB model is based in the resolution of town surface energy balances. For the area not impacted by passing vehicles, the energy balance corresponded to the initial TEB configuration. However, in the area impacted by the traffic, the physical processes of traffic were substituted for the road surface parameters. Then, a weighted average of RST was calculated with the surface temperatures from the resolution of the energy balances. The ponderation is based on $Z_{\text {traffic }}$, a constant between 0 and 1 . It represents the percentage of the road impacted by the vehicle passage (Fig. 4c).

To integrate traffic simply and relevantly into the TEB model, some assumptions were made. First, the heat flux generated by the engine $S_{\mathrm{m}}$, the exhaust system $E_{\mathrm{ex}}$ and the flow of forced convection $S_{\mathrm{va}}$ generated by passing vehicles are added to the urban canyon $Q_{\mathrm{H}_{-} \text {TOP }}$ and $Q_{\mathrm{E}_{-} \text {TOP }}$. Then, the heat friction flux $S_{\mathrm{t}}$ is added to the road surface energy balance. This energy contribution is taken into account in the most appropriate location of the urban canyon, along with its interaction with the flux of other components (road, walls). Concerning the radiative flux, the infrared radiation flux emitted by the vehicle is added to the infrared radiative flux received by the road surface. The infrared flux emitted by the bottom of the vehicle $F_{\mathrm{IR}}$ veh inf is added to the longwave radiation flux received by the road surface $R_{\mathrm{ld}}$, and the infrared flux emitted by the upper part of the vehicle $F_{\mathrm{IR} \_ \text {veh_sup }}$ is added to the long wavelength flux of the atmosphere $R_{\text {lu }}$. The shield effect caused by passing vehicles will decrease the radiative flux of the road surface. Based on these assumptions, the road surface energy balance is written in the following form:

$$
\begin{aligned}
(\rho c)_{\text {road }} \frac{\partial \mathrm{RST}}{\partial t} \Delta Z_{\mathrm{s}} & =\left(1-Z_{\text {traffic }}\right)\left(R_{\mathrm{n}}+S_{\mathrm{a}}+L+G\right) \\
& +Z_{\text {traffic }}\left(R_{\mathrm{n}}^{*}+S_{\mathrm{a}}^{*}+L^{*}+G\right. \\
& \left.-C_{\text {shield }} S_{\text {va }}+0.22 C_{\text {shield }} S_{\mathrm{t}}\right) .
\end{aligned}
$$

The $\left({ }^{*}\right)$ symbol denotes surface parameters impacted by traffic. The constant 0.22 represents the impact factor defined by Khalifa et al. (2014) for the tire frictional processes (Table 2). The net radiation impact on traffic $R_{\mathrm{n}}^{*}$ is expressed by the following equations:

$R_{\mathrm{n}}^{*}=R_{\mathrm{nl}}^{*}+R_{\mathrm{ns}}$,

$R_{\mathrm{nl}}^{*}=R_{\mathrm{ld}}^{*}+R_{\mathrm{lu}}^{*}$,
$R_{\mathrm{ld}}^{*} \cong\left(1-C_{\text {shield }}\right) R_{\mathrm{ld}}+C_{\text {shield }} R_{\mathrm{IR} \_ \text {veh_inf }}$,

$R_{\mathrm{lu}}^{*} \cong\left(1-C_{\text {shield }}\right) R_{\text {lu }}+C_{\text {shield }} R_{\mathrm{IR} \_ \text {veh_sup }}$.

The sensible $S_{\mathrm{a}}^{*}\left(\mathrm{~W} \mathrm{~m}^{-2}\right)$ and latent $L^{*}\left(\mathrm{~W} \mathrm{~m}^{-2}\right)$ heats in the presence of traffic on the road are, respectively, written as

$S_{\mathrm{a}}^{*}=\rho_{\text {air }} \mathrm{AC}_{\text {road }}^{*}\left(\mathrm{RST}-T_{\text {lowcan }}\right)$,

$L^{*}=\rho_{\text {air }} \mathrm{AC}_{\text {road-watt }}^{*}\left(Q_{\text {sat_road }}-Q_{\text {canyon }}\right)$.

According to the first hypothesis of integration of traffic impacts, the heat flows through the engine and the exhaust system are added to the turbulent heat flux of the urban canyon, which influences the road surface energy balance. This is reflected by means of the following equations:

$$
\begin{gathered}
Q_{\mathrm{H} \_\mathrm{TOP}}=Q_{\mathrm{H}-\mathrm{ROAD}}+2 \frac{h}{w} Q_{\mathrm{H}-\mathrm{WALL}} \\
+C_{\text {shield }} \frac{1}{f_{\text {road }}} Q_{\mathrm{H}-\mathrm{TRAFFIC}}, \\
Q_{\mathrm{H} \_ \text {TRAFFIC }}=0.25 S_{\mathrm{m}}+0.21 S_{\mathrm{ex}}+S_{\mathrm{va}} .
\end{gathered}
$$

The constants 0.25 and 0.21 represent the impact factor defined by Khalifa et al. (2014) for the engine and the exhaust system, respectively (Table 2). An exhaustive list of abbreviations is provided in Appendix A, giving the all terms used in equations for both this article and that of Khalifa et al. (2014).

\section{Experimental measurements of traffic effect on urban RST}

To identify the most appropriate approach to implementing traffic in the TEB, some experiments were conducted. They consisted in RST measurements on pavement zones subjected and not subjected to traffic. The experimental zone was located in rue Charles III (Nancy, France), having a canyon configuration consistent with TEB, with a width around $12 \mathrm{~m}$ (Fig. 5). This street is straight, orientated slightly north of west-east, and consisting of one non-circulated lane, nearly $3 \mathrm{~m}$ wide, and two circulated lanes to give a total width of nearly $9 \mathrm{~m}$, and with a one-directional vehicle flow going east.

\subsection{Description of the experiments, meteorological and traffic data}

RST and atmospheric measurements were obtained using a vehicle parked in the selected street with an on-board data acquisition system (Fig. 6a). The instruments were primarily devices dedicated to meteorological parameters $\left(T_{\text {air }}\right.$, relative humidity, wind direction and speed). They were installed 


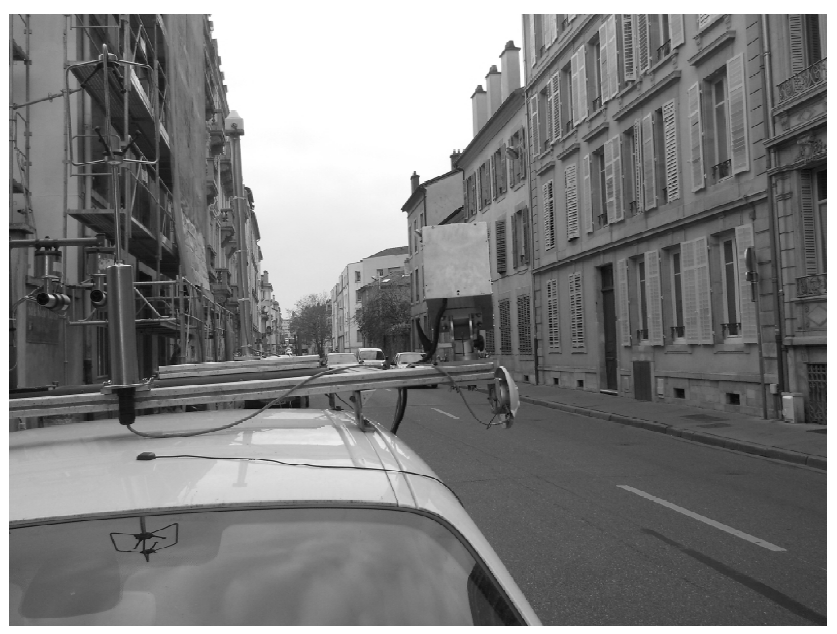

Figure 5. Configuration of the street in Nancy (France) for the validation of the two different approaches to traffic implementation in TEB.

on the roof of the vehicle, and data collected every $2 \mathrm{~s}$. A radiometer and an infrared camera were dedicated to RST without and with traffic, respectively. The radiometer was installed in a compartment at controlled temperature, attached to the front bumper of the car, also with measurements every $2 \mathrm{~s}$. The infrared camera was installed in a compartment on the vehicle roof. Thermal images of the pavement submitted to traffic were taken every $60 \mathrm{~s}$. An illustration of instruments is given in Fig. 6b. Traffic data for the selected street were obtained from the appropriate department in Nancy.

Two experiments were then conducted. They consisted in continuously monitoring all the parameters described above over a period of up to $48 \mathrm{~h}$ in the same locations and on two distinct dates, and with a variety of weather situations corresponding to an approaching winter.

\subsection{Weather and urban data inputs for TEB}

Meteorological data used as forcing input for the TEB surface model come from the Nancy weather station located $2800 \mathrm{~m}$ away from the measurement site. Measurements available and used from this station are air temperature at $2 \mathrm{~m}$ height $\left({ }^{\circ} \mathrm{C}\right)$, air relative humidity at a height of $2 \mathrm{~m}(\%)$ (the specific humidity used for forcing was calculated from this relative humidity), wind speed at a height of $10 \mathrm{~m}\left(\mathrm{~m} \mathrm{~s}^{-1}\right)$, direct and diffuse solar radiation $\left(\mathrm{W} \mathrm{m}^{-2}\right)$, rain and snow precipitation $(\mathrm{mm})$ and air pressure $(\mathrm{Pa})$. In the absence of coupling with an atmospheric model, TEB can be forced with meteorological parameters at $2.5 \mathrm{~m}$. It was therefore consistent to take meteorological measurements available at $2 \mathrm{~m}$ as forcing data. Direct and diffuse radiation was calculated by the TEB model on the basis of global radiation data, assuming $80 \%$ as direct and the $20 \%$ remaining as diffuse. These data cover both measurements campaigns with an hourly time step. The first campaign started on 20 November 2014

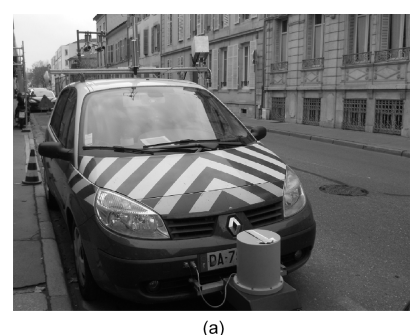

(a)

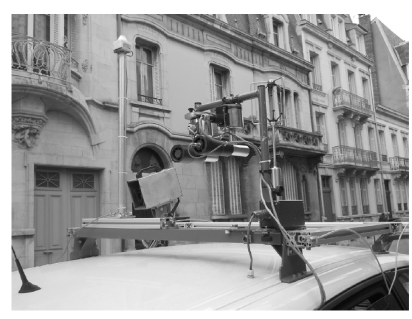

(b)
Figure 6. Illustration of a car parked in the street with the radiometer on the front bumper (a), and details of instruments installed on the vehicle roof.

at 04:00 (local time) and lasted $48 \mathrm{~h}$, and the second campaign was initiated on 17 December 2014 at 11:00 and lasted $30 \mathrm{~h}$.

Besides these meteorological parameters, the TEB scheme requires a parameterization of the coatings constituting the built urban area, such as the percentage of built area, the height of buildings, the road width, the number of component layers of each covered urban surface (roof, walls and road), their thickness, and their thermal characteristic (thermal conductivity and heat capacity). The selected elements were the ones initially present in the TEB urban data input and considered as consistent with the building configuration of the experimental site. Some of these are provided in Table 3 , and the selected building density was $70 \%$.

\section{Results and discussion}

\subsection{Experimental results on RST}

The first step in our experimental study is to assess the magnitude of the traffic impact on the road surface temperature. Figure 7 indicates the RST of an area without traffic and the one subjected to traffic. It is noted that outside peak hours between the 20:00 and 06:00 RST curves merge for the two zones. This reflects the reduced traffic flux input. However, during the day, we found that the RST of the area subjected to traffic is greater by 1 to $3{ }^{\circ} \mathrm{C}$ with respect to the noncirculated one. The higher the traffic (especially during peak hours), the larger the gap between the two RSTs. The preliminary result of this experimental study confirms those reported in the literature (Gustavsson et al., 2001; Fujimoto et al., 2008). Firstly the RST differences do not only exist between an urban configuration and a rural one. The RST is also greater in a zone subjected to traffic with respect to another one that is traffic-free. This was observed in a full urban configuration. There is a clear relationship between hourly variation of thermal traffic contribution (Fig. 3) and hourly RST variation too.

The TEB model simulates an average RST. It does not distinguish between an area impacted by passing vehicles and another one without traffic. In order to compare the results 
Table 3. Examples of parameterization of the coatings constituting the built urban area in TEB.

\begin{tabular}{|c|c|c|c|c|}
\hline Item & \multicolumn{2}{|r|}{ Value } & \multicolumn{2}{|c|}{ Unit } \\
\hline Percentage of built area & \multicolumn{2}{|r|}{70} & \multicolumn{2}{|c|}{$(\%)$} \\
\hline Building height & \multicolumn{2}{|r|}{15} & \multicolumn{2}{|c|}{$(\mathrm{m})$} \\
\hline Ratio of the width of the canyon and urban building height & \multicolumn{2}{|r|}{1.15} & \multicolumn{2}{|c|}{-} \\
\hline \multicolumn{5}{|c|}{ Characteristics of the various components of the urban canyon } \\
\hline & & Roof & Road & Walls \\
\hline Emissivity & & 0.90 & 0.94 & 0.90 \\
\hline Albedo & & 0.22 & 0.08 & 0.20 \\
\hline Number of layers & & 4 & 5 & 4 \\
\hline \multirow[t]{5}{*}{ Layer thickness (m) } & 1 & 0.020 & 0.001 & 0.010 \\
\hline & 2 & 0.150 & 0.010 & 0.040 \\
\hline & 3 & 0.120 & 0.100 & 0.015 \\
\hline & 4 & 0.300 & 0.250 & 0.060 \\
\hline & 5 & - & 0.600 & - \\
\hline \multirow[t]{5}{*}{ Layer heat capacity $\left(\mathrm{W} \mathrm{K}^{-1} \mathrm{~m}^{-2}\right)$} & 1 & 1769000 & 2000000 & 1890000 \\
\hline & 2 & 1500000 & 2000000 & 1890000 \\
\hline & 3 & 290000 & 2000000 & 804000 \\
\hline & 4 & 1520000 & 2000000 & 564000 \\
\hline & 5 & & 1400000 & \\
\hline \multirow[t]{5}{*}{ Layer thermal conductivity $\left(\mathrm{W} \mathrm{m}^{-1} \mathrm{~K}^{-1}\right)$} & 1 & 0.90 & 2.00 & 1.77 \\
\hline & 2 & 0.93 & 2.00 & 1.77 \\
\hline & 3 & 0.50 & 2.00 & 0.75 \\
\hline & 4 & 0.19 & 2.00 & 0.18 \\
\hline & 5 & - & 0.40 & - \\
\hline
\end{tabular}

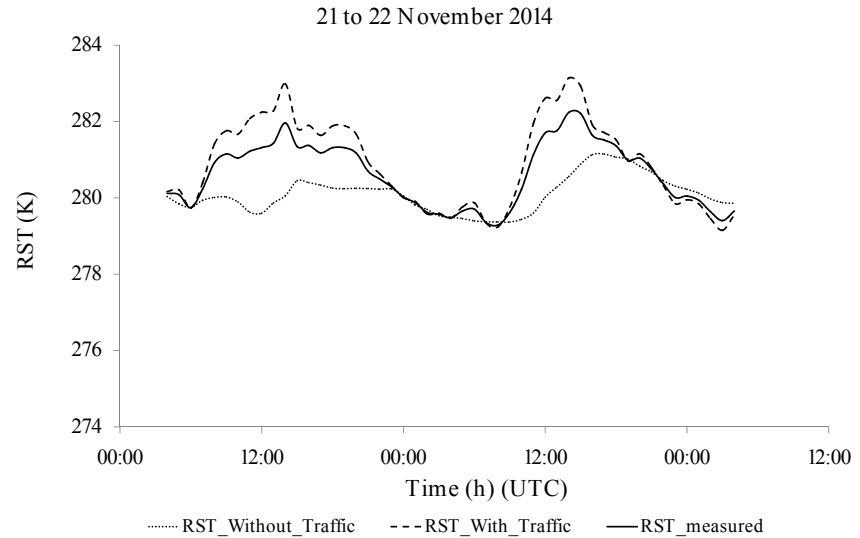

Figure 7. Assessment of the magnitude of traffic impacts on the RST, and illustration of a weighted average temperature of the road surface for the first experiment.

provided by the TEB model with field data, we calculated a weighted average RST. In the following text, the measured road surface temperature $\mathrm{RST}_{\text {measured }}$ corresponds to this weighted average RST according to the following relationship:

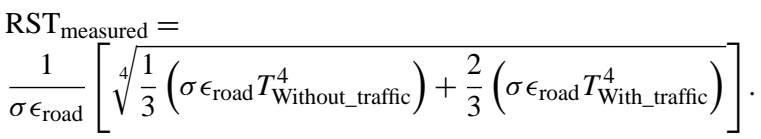

The constants $1 / 3$ and $2 / 3$ correspond to the portion of the road without traffic and the one subjected to traffic, respectively. These values are consistent with the numerical description of the second approach, $1-Z_{\text {traffic }}$ and $Z_{\text {traffic }}$, respectively. Therefore, in the text that follows, the results of the TEB model on RST will be compared to RST measured. Its variations with time for the first experiment are illustrated in Fig. 7.

\subsection{Assessment of air canyon simulation with TEB in its initial configuration}

The next step in our study, and in the first one in the evaluation of the TEB parametrization, was to check the ability of TEB to simulate the air canyon temperature in a street without traffic. As indicated in the literature, some experiments have been conducted over circulated and noncirculated zones (Lemonsu et al., 2008, 2010). TEB has already been validated to simulate the air canyon temperature 
for a street without traffic, or with heat flux from traffic neglected (Leroyer et al., 2010). The comparison between field measurements in Nancy and simulation results of $T_{\text {air }}$ with the TEB model in its initial configuration (IC) is illustrated in Fig. 8a. At nighttime, there is no traffic in rue Charles III, and TEB provided results in good agreement with field data.

\subsection{Comparison between RST from TEB in its initial configuration and field data}

As indicated above, in the initial configuration of the TEB model, traffic heat flux was already introduced. It was considered as a constant flux that is added to the heat flux of the urban canyon according to a simple diurnal cycle. Figure 8a provides a comparison between the RST simulated by the TEB model via the initial configuration of traffic

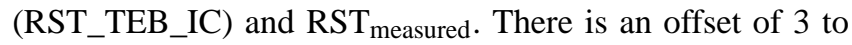
$4{ }^{\circ} \mathrm{C}, \mathrm{RST}$-measured being greater than the RST_TEB_IC. This initial configuration does not properly take into account this traffic heat flux. This offset can be explained either by an incorrect traffic heat values input, or by inadequate integration of traffic into the TEB model. Additional calculations were then made to evaluate to what extent the value of the heat flux generated by the traffic could be adjusted to obtain the best RST forecast. Values up to $200 \mathrm{~W} \mathrm{~m}^{-2}$ were considered and results plotted in Fig. 8c. They show that none of the values was enough to obtain the experimental results. Increasing $Q_{\text {traffic }}$ up to $200 \mathrm{~W} \mathrm{~m}^{-2}$ was not enough to reach a coincidence between $\mathrm{RST}_{\text {measured }}$ and RST_TEB_IC curves, the offset remaining nearly $2^{\circ} \mathrm{C}$. Furthermore, the traffic peaks are not as visible as in field measurements, nor is the relationship with $Q_{\text {traffic }}$ (Fig. 3). The RST increase is not as great as expected due to $Q_{\text {traffic }}$ increase during peak hours. Moreover, such $Q_{\mathrm{H}_{-} \text {traffic }}$ values not only do not improve the modeling of the RST, but they also disrupt the Tair modeling, as illustrated in Fig. 8d. While taking into account the heat flux generated by the traffic according to the initial configuration value of $Q_{\mathrm{H} \_ \text {traffic }}=20 \mathrm{~W} \mathrm{~m}^{-2}$ gave $T_{\text {air }}$ results consistent with the measurements, the allocation of larger values $\left(Q_{\mathrm{H}_{-} \text {traffic }}=50,100,150\right.$, and $\left.200 \mathrm{~W} \mathrm{~m}^{-2}\right)$ induce disruption in the corresponding $T_{\text {air }}$. The results of Fig. 8c and d also justify the purpose for which the traffic was integrated into the TEB model. In fact, the heat flux generated by the traffic was included under this initial configuration for modeling the overall heat flow in the urban canyon, to assess the specific impact of anthropogenic heat flux on urban comfort. This initial configuration of traffic in the TEB model may be valid according to the objective for which it was taken into account, but it does not meet the objective of our study about the evaluation of traffic thermal impacts on the RST modeling. This method should be modified to better take into account traffic heat inputs, especially in winter conditions. This initial parameterization of traffic into the TEB model was not meant for RST forecast but more for global heat flux balance of a urban canyon (Pigeon et al., 2008).

\subsection{Traffic integration results with the first approach}

The constants of the traffic heat input set out in the initial configuration of traffic in TEB were not adapted with respect to flux generated by the traffic and indicated in the literature for the RST forecast (Sailor and Lu, 2004; Pigeon et al., 2007, 2008; Colombert, 2008). The first approach (A1) consists in introducing a more accurate heat flux generated by vehicles, expressed in $\mathrm{W} \mathrm{m}^{-2}$ of road, with its daily cycle presented in Fig. 3, and then in testing the sensitivity of the road energy balance variation in this. Figure $8 \mathrm{a}$ illustrates the variations with time of $\mathrm{RST}_{\text {measured, }}$ $R S T \_T E B \_I C$ and the RST simulated according to the (A1) approach (RST_TEB_Al) in the case of the first experiment. Similar results were obtained with the second experiment.

The integration of traffic into the TEB model according to the (A1) approach did not affect the $T_{\text {air }}$ forecast with respect to the initial configuration (Fig. 8a), and has led to a slight improvement in the RST forecast (Fig. 8b). However, this improvement did not manage to reach the values as observed in field data. The modification of this first approach mainly involved having a daily variation of traffic heat into the canyon that was nearly $40 \mathrm{~W} \mathrm{~m}^{-2}$ greater (Fig. 3) at a given time of day. This change in energy, without significantly modifying its daily cycle, slightly increased the RST. It might also reveal some missing energy from the traffic.

The study of the thermal mapping of traffic impacts carried out by Khalifa et al. (2014) indicated that the maximum effect of traffic is generated by the tire friction and the sensible heat flux exchanged between the vehicle and the road surface. It also indicates that the maximum traffic effect occurs in the immediate vicinity of the vehicle, approximately $0.5 \mathrm{~m}$ from the ground. In the TEB model, the urban canyon heat flux interacts at the first level of TEB located at a height of $2 \mathrm{~m}$ from the ground. This integration of traffic as a source of heat in the urban canyon is therefore not suitable. This description of the first approach may also be valid in the case of a global appreciation of anthropogenic flux.

\subsection{Traffic integration results with the second approach}

\subsubsection{Analysis of results}

Traffic integration results using this second approach (A2) are illustrated in Fig. 9. This compares the variation with time of RST for a traffic integration in the TEB as in the initial configuration and according to the (A2) approach for both experiments. RST results with the (A2) approach (RST_TEB_A2) are closer to the field data than the initial configuration. The difference between field and calculated RST is nearly $0.5^{\circ} \mathrm{C}$ on average. RST variations reflect those of $Q_{\text {traffic }}$ (Fig. 3), and their amplitudes $\left(3^{\circ} \mathrm{C} \mathrm{Fig.} \mathrm{9a;}\right.$ $6^{\circ} \mathrm{C}$ Fig. 9b) are consistent with field measurements. The $R S T \_T E B_{-} A 2$ profile indicates that this approach took the heat inputs generated by traffic more properly into account. 


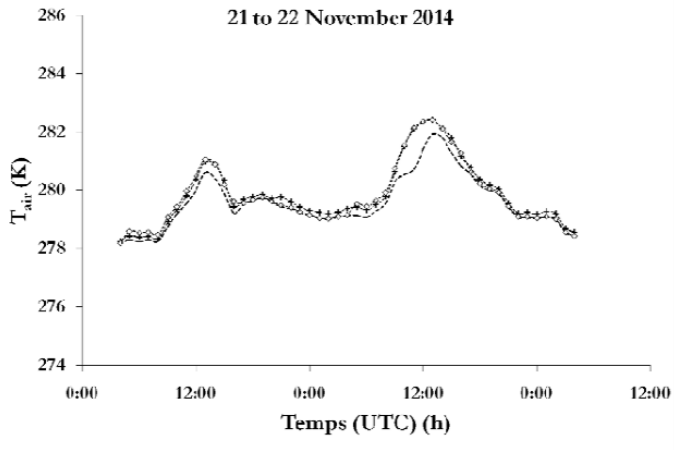

$\rightarrow-$ Tair_mesurée ----Tair_TEB_IC $\rightarrow$-Tair_TEB_A1

(a)

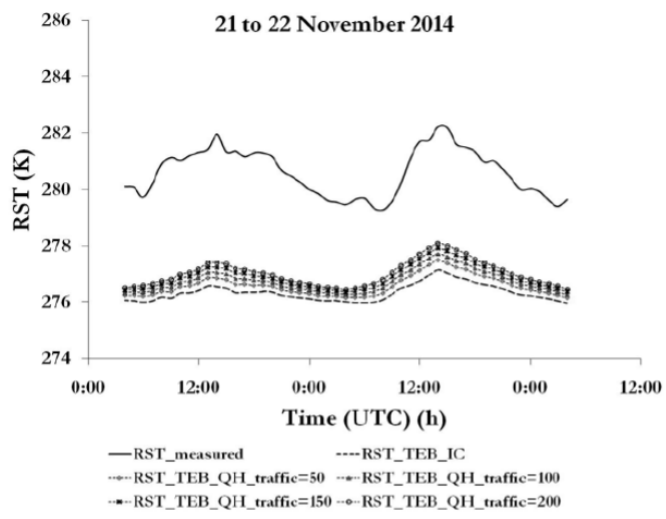

(c)

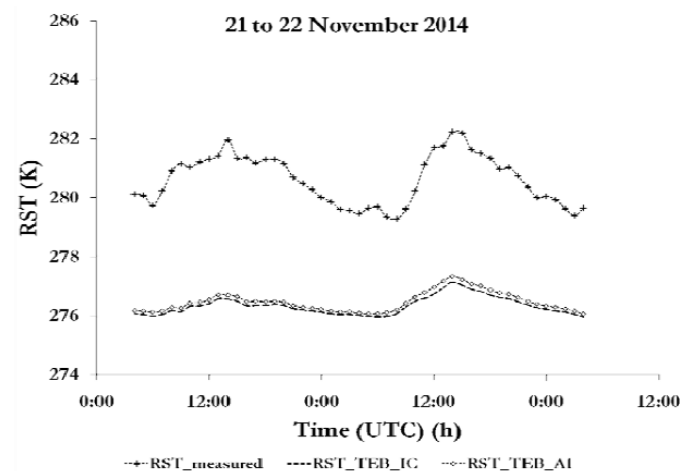

(b)

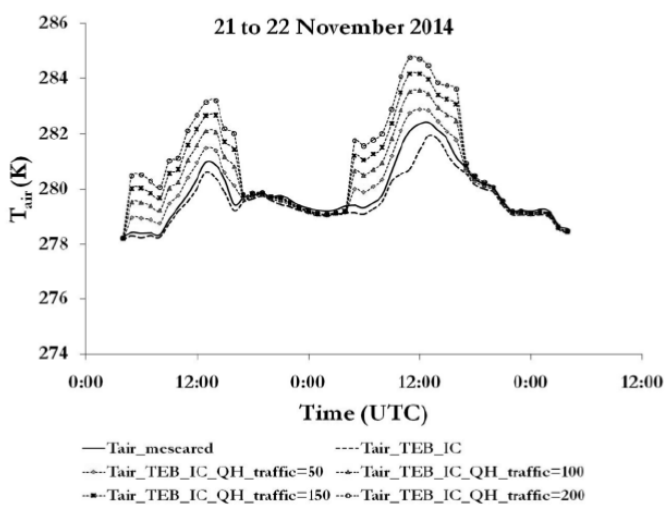

(d)

Figure 8. Comparisons between $T_{\text {air }}$ from TEB in its initial configuration (Tair_TEB_IC), $T_{\text {air }}$ from TEB via the first approach (Tair_TEB_A1) and field data (Tair_measured) (a), between RST from TEB in its initial configuration (RST_TEB_IC), RST from TEB via the first approach (RST_TEB_A1) and field data (RST_measured) (b), evaluation of the incidence of the traffic energy flux value on RST from TEB in its initial configuration (c), and disruption induced on Tair forecast from TEB in its initial configuration with larger values of QH_traffic (d) for the first experiment.

We also found that heat input peaks of the traffic during rush hours were obtained with better agreement with respect to field measurements.

Analysis of the RST_TEB_A2 shows that the RST forecast is improved by 2 to $3^{\circ} \mathrm{C}$ with respect to $R S T \_T E B \_I C$. This improvement primarily reflects the impacts of traffic on the RST and also that the configuration with which the traffic was introduced into the TEB model seems more appropriate for the case of the winter season. Although the experiments were conducted above freezing, RST is still underestimated and might lead to false alerts with respect to ice occurrence. This could be critical in the early commuting hours of the day, and some work is still needed to improve the mitigation of road hazards due to iced roads.

Another validation of the (A2) approach involved comparing the air temperature measured on the vehicle in the street with the forecast one obtained with TEB. Air temperature measurements are obtained at a height $(1.8 \mathrm{~m})$ and under conditions (generation of a continuous laminar air flow on the probe) compliant with those at which TEB provides its re- sults $(2 \mathrm{~m})$. Results are presented in Fig. 10, and indicated good agreement between the forecast and the measurement in both experimental cases.

\subsubsection{Model sensitivity}

As indicated before, the TEB model provides an average RST and does not distinguish between an area subjected to traffic and another one that is not.

The parameter $Z_{\text {traffic }}$ was integrated into the model to take into account the portion of the road affected by traffic. The sensitivity test of the TEB model to this parameter, $Z_{\text {traffic }}$, was conducted. $Z_{\text {traffic }}=1$ corresponds to the measurements made by the infrared camera (RST_With_traffic). Figure 11 indicates that the results given by the TEB model $\left(R S T \_T E B \_A 2\left(Z_{\text {traffic }}=1\right)\right)$ are close to $R S T \_W i t h \_t r a f f i c$. This confirms that the physical description of the traffic impacts process is suitable for the traffic integration in the TEB model for the winter season. 

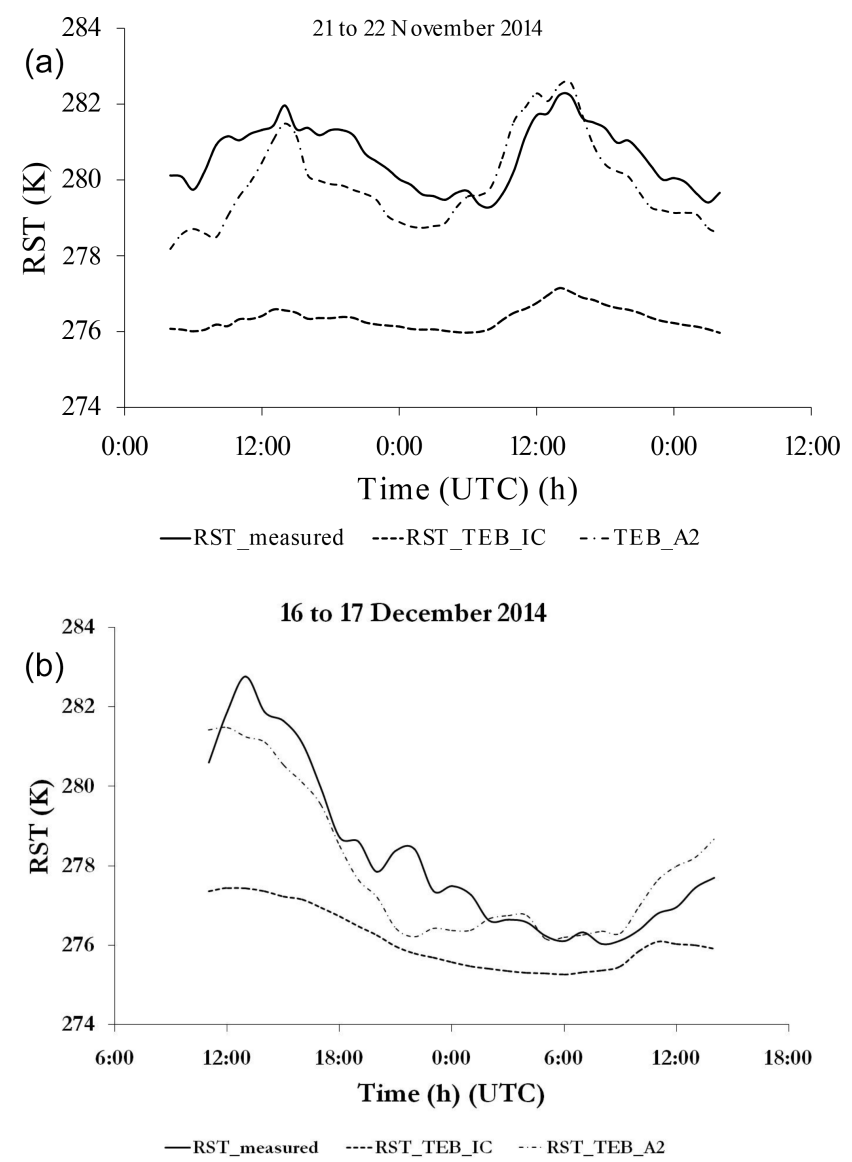

Figure 9. Comparison between RST from TEB in its initial configuration (RST_TEB_IC), RST from TEB via the first approach (RST_TEB_A1), RST from TEB via the second approach (RST_TEB_A2) and field data (RST_measured) for the first (a) and for the second (b) experiments.

In urban areas, besides meteorological parameters, the RST is also influenced by the buildings' configuration (percentage of buildings, building heights, widths of roads, type of materials used, etc.). Specific configurations where buildings are present everywhere in an urban environment, or totally absent, though not applicable in all urban environments, were tested to evaluate the sensitivity of the TEB model to this parameter. The results are shown in Fig. 12. It is found that without building the RST decreases by $0.5^{\circ} \mathrm{C}$, especially at night. This can be explained by the nature of the building materials that store heat during the day and restore it at the night along with the absence of a radiative well created by buildings. In the absence of buildings, the heat transfer phenomenon is absent.

\section{Conclusions}

An experimental study was conducted to quantify the anthropic energy flux of traffic impact on RST in the winter
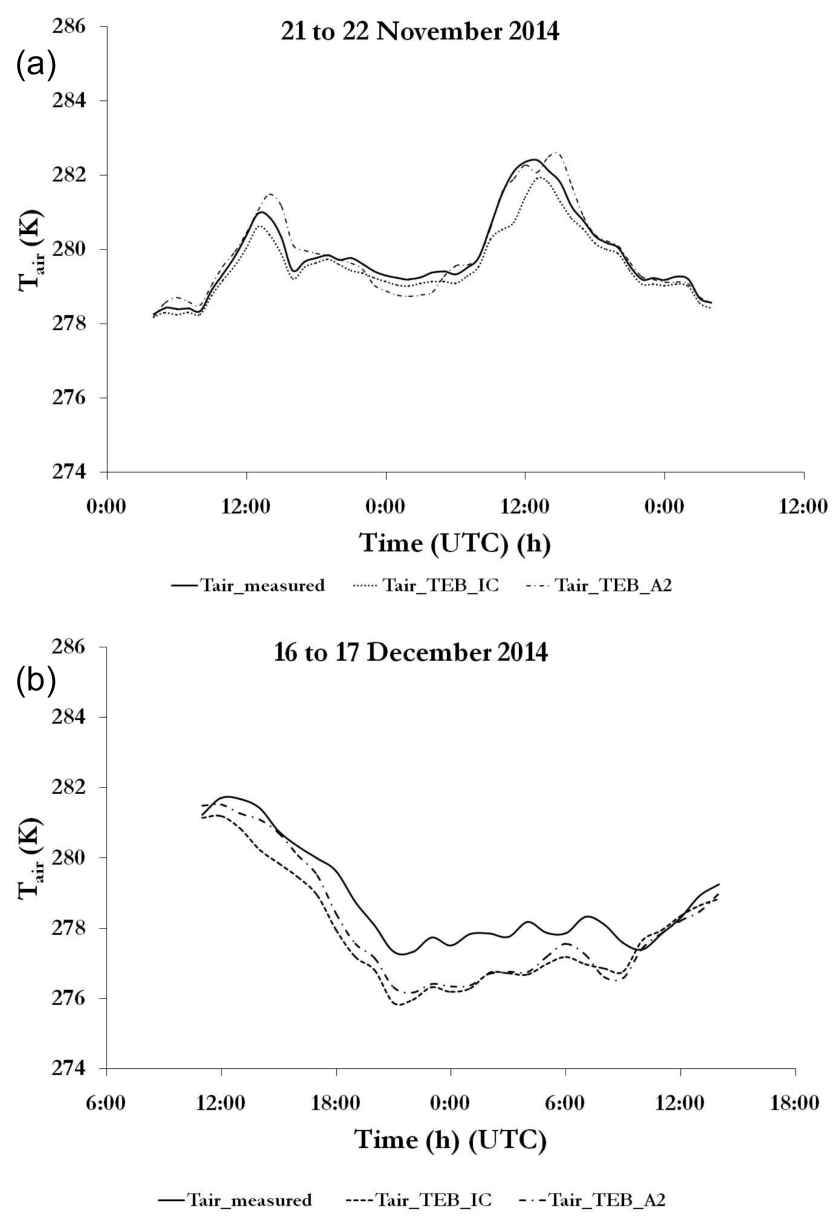

Figure 10. Comparison between air temperature from TEB in its initial configuration (Tair_TEB_IC), air temperature from TEB via the first approach (Tair_TEB_A1), air temperature from TEB via the second approach (Tair_TEB_A2) and air temperature from field data (Tair_measured) for the first (a) and for the second (b) experiments.

season. It indicated an RST increase by 1 to $3{ }^{\circ} \mathrm{C}$ with respect to the absence of traffic. Additional work was undertaken to evaluate to what extent an accurate description of traffic might improve the TEB numerical model when dedicated to RST simulations. Two approaches to traffic integration in this model were detailed and tested.

The integration of traffic into the TEB model according to the first approach (A1) and based on a variable heat flux into the canyon with time did not improve RST forecasting, with a gap between simulations and measurements of 3 to $4{ }^{\circ} \mathrm{C}$. This approach can be used to evaluate the global anthropogenic heat flux in the urban canyon, and is not meant for RST urban simulation. The results of the second approach (A2), consisting in an accurate description of energy contributions of traffic, were consistent with the experimental study as well as with the literature review. They indicated that the traffic increased RST by 1 to $3{ }^{\circ} \mathrm{C}$, and this increase 


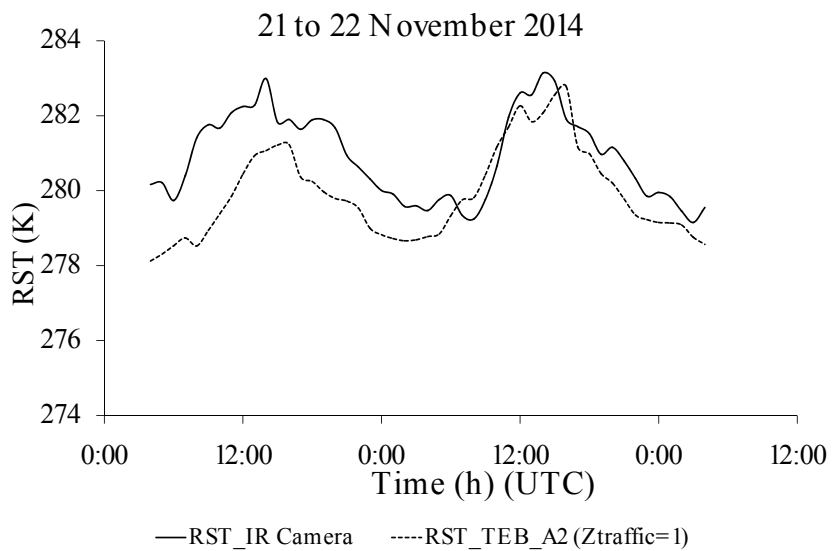

Figure 11. Comparison between RST measured by the IR camera in an area impacted by traffic and RST from TEB via the second approach with $Z_{\text {traffic }}=1$ for the first experiment.

depends on traffic conditions (vehicle velocity, traffic density and traffic impact area). Some TEB model sensitivity tests showed that the traffic impact area affects the RST forecast. If this area is large, the thermal traffic flows are great, which results in an increase in the RST. The presence or absence of buildings also influenced modeling of RST. Validation was also successfully obtained with the air temperature. These results were obtained in some winter situations not considered as critical. RST is still slightly underestimated in this second approach, and could therefore trigger false alerts of ice occurrence on pavement. To obtain a better forecast for RST with the TEB model, it is necessary to properly define the configuration of the urban environment. It should be noted that the integration of traffic in the TEB model according to this second approach significantly improved the RST forecast in the winter season. However, there is still a difference of 0.5 to $1{ }^{\circ} \mathrm{C}$ between the measurements and the TEB-simulated RST. This can be explained either by the error that can be assigned to the measurement devices, or because the physical description we used for the process of traffic impacts still needs improvement, or by the existence of certain road parameters that have not yet been introduced into the RST forecast with this model.

An assumption was made about the energy absorbed by passing vehicles, which was included in the pavement as a first approximation. Such a hypothesis will limit the modeling to non-heavy traffic streets $\left(C_{\text {shield }}<0.5\right.$, as is the case in Nancy) and to winter situations with low shortwave radi-

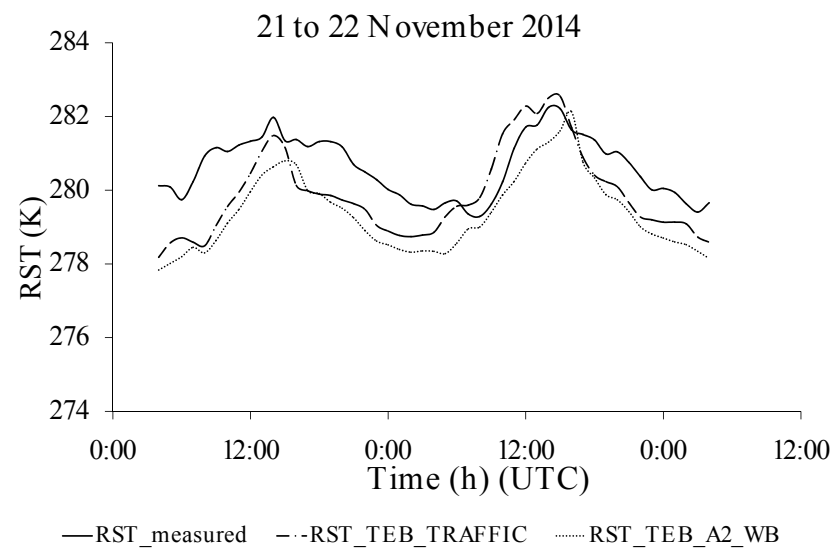

Figure 12. Comparison between RST from TEB via the second approach (RST_TEB_A2), RST from TEB via the second approach without buildings (RST_TEB_A2_WB) and field data (RST_measured) for the first experiment.

ation flux. The implementation of traffic in the TEB model will certainly be improved by considering a full energy balance description of the vehicles (shortwave and longwave radiation). If some parts of this energy (infrared flux emitted by the lower part of the vehicles) will still be added to the pavement, other ones (shortwave downward radiation flux absorbed by their upper parts) will certainly be included in the sensible heat flux of the canyon.

Within the same context of this study, further work will be undertaken to analyze the sensitivity of the TEB model to these different physical processes of traffic, and on the basis of additional field data currently available. The objective is to assess the contribution of each traffic process in improving the RST modeling according to the traffic parameters and the variation of atmospheric stability. These thermal traffic impacts should also be coupled with the road surface water balance of the TEB model to identify and further quantify the influence of the presence of water in its various forms (liquid and solid (ice and snow)) on the RST modeling. Furthermore, the energy absorbed by vehicles has so far been added to the road surface, which was consistent with winter situations and the traffic profiles used. So as to extend the approach to other seasons, a detailed description of energy absorbed by passing vehicles will have to be considered. 


\section{Appendix A: List of abbreviations}

\begin{tabular}{|c|c|c|}
\hline Abbreviations & Synonym & Unit \\
\hline$a_{\text {veh_sup }}$ & Albedo of the upper part of a vehicle & - \\
\hline$a_{\text {veh_inf }}$ & Albedo of the lower part of a vehicle & - \\
\hline $\mathrm{AC}_{\text {road }}$ & Aerodynamic conductance on a dry road & - \\
\hline $\mathrm{AC}_{\text {road-wat }}$ & Aerodynamic conductance on a wet road & - \\
\hline $\mathrm{AC}_{\text {road }}^{*}$ & Aerodynamic conductance impacted by traffic on a dry road & - \\
\hline $\mathrm{AC}_{\text {road-wat }}^{*}$ & Aerodynamic conductance impacted by traffic on a wet road & - \\
\hline$C_{\text {ex }}$ & Specific heat of combustion products & $\mathrm{J} \mathrm{kg}^{-1} \mathrm{~K}^{-1}$ \\
\hline$C_{\text {shield }}$ & Shield coefficient & - \\
\hline$C_{\text {turb }}$ & Coefficient of turbulence caused by traffic & - \\
\hline$c_{p}$ & Specific heat capacity & $\mathrm{J} \mathrm{kg}^{-1} \mathrm{~K}^{-1}$ \\
\hline$d_{1}, d_{2}$ & Thickness of the first and the second layer of the road & $\mathrm{m}$ \\
\hline$D_{\text {veh }}$ & Traffic density & vehicles $\mathrm{s}^{-1}$ \\
\hline$E_{\mathrm{ex}}$ & Sensible heat flux from the exhaust system & $\mathrm{W} \mathrm{m}^{-2}$ \\
\hline FE & Average fuel consumption & $\mathrm{km} \mathrm{L}^{-1}$ \\
\hline FIR $_{\text {veh-inf }}$ & Downward infrared radiation flux emitted by the lower part of vehicle & $\mathrm{W} \mathrm{m}^{-2}$ \\
\hline FIR $_{\text {veh-sup }}$ & Upward infrared radiation flux emitted by the upper part of vehicle & $\mathrm{W} \mathrm{m}^{-2}$ \\
\hline$G$ & Conductive soil heat flux & $\mathrm{W} \mathrm{m}^{-2}$ \\
\hline$h$ & Representative height of urban canyon in the TEB model & $\mathrm{m}$ \\
\hline$L$ & Latent heat flux & $\mathrm{W} \mathrm{m}^{-2}$ \\
\hline$L^{*}$ & Latent heat flux impacted by traffic & $\mathrm{W} \mathrm{m}^{-2}$ \\
\hline$L_{\mathrm{V}}$ & Latent energy of liquid water evaporation & $\mathrm{J} \mathrm{kg}^{-1}$ \\
\hline$L_{\mathrm{veh}}$ & Vehicle length & $\mathrm{m}$ \\
\hline LW Road_to_Road & Interaction radiative coefficient between road and road & $\mathrm{W} m-2 \mathrm{~K}^{-4}$ \\
\hline LW Road_to_Sun & Interaction radiative coefficient between road and sun & $\mathrm{W} m-2 \mathrm{~K}^{-4}$ \\
\hline $\mathrm{LW}_{\text {Snow_to_road }}$ & Interaction radiative coefficient between snow and road & $\mathrm{W} m-2 \mathrm{~K}^{-4}$ \\
\hline LW Walls_to_road & Interaction radiative coefficient between walls and road & $\mathrm{W} m-2 \mathrm{~K}^{-4}$ \\
\hline $\mathrm{LW}_{\text {Garden_to_road }}$ & Interaction radiative coefficient between garden and road & $\mathrm{W} \mathrm{m}-2 \mathrm{~K}^{-4}$ \\
\hline$m_{\mathrm{ex}}$ & Combustion product mass flow rate & $\mathrm{kg} \mathrm{s}^{-1}$ \\
\hline$m_{\mathrm{H}_{2} \mathrm{O}}$ & Water vapor mass fraction in the exhaust system & - \\
\hline $\mathrm{NHC}$ & Net heat combustion & $\mathrm{J} \mathrm{kg}^{-1}$ \\
\hline$Q_{\text {canyon }}$ & Specific air humidity & $\mathrm{g} \mathrm{kg}^{-1}$ \\
\hline$Q_{\text {E_traffic }}$ & Latent heat flux of traffic & $\mathrm{W} \mathrm{m}^{-2}$ \\
\hline$Q_{\text {E_top }}^{-}$ & Latent heat flux of urban canyon & $\mathrm{W} \mathrm{m}^{-2}$ \\
\hline$Q_{\mathrm{H} \_t r a f f i c}$ & Sensible heat flux of traffic & $\mathrm{W} \mathrm{m}^{-2}$ \\
\hline$Q_{\mathrm{H} \_ \text {top }}$ & Sensible heat flux of urban canyon & $\mathrm{W} \mathrm{m}^{-2}$ \\
\hline$Q_{\text {traffic }}$ & Total heat flux generated by traffic & $\mathrm{W} \mathrm{m}^{-2}$ \\
\hline$Q_{\text {sat_road }}$ & Specific humidity of the road surface & $\mathrm{g} \mathrm{kg}^{-1}$ \\
\hline$Q_{\mathrm{v}}$ & Global flux from a vehicle & $\mathrm{J} \mathrm{s}^{-1}$ \\
\hline$R_{\mathrm{n}}$ & Net radiation flux & $\mathrm{W} \mathrm{m}^{-2}$ \\
\hline$R_{\mathrm{nl}}$ & Net longwave radiation at the road surface & $\mathrm{W} \mathrm{m}^{-2}$ \\
\hline$R_{\mathrm{nl}}^{*}$ & Net longwave radiation at the road surface impacted by traffic & $\mathrm{W} \mathrm{m}^{-2}$ \\
\hline$R_{\mathrm{ns}}$ & Net shortwave radiation at the road surface & $\mathrm{W} \mathrm{m}^{-2}$ \\
\hline$R_{\mathrm{ld}}$ & Downward longwave radiation at the road surface & $\mathrm{W} \mathrm{m}^{-2}$ \\
\hline$R_{\mathrm{ld}}^{*}$ & Downward longwave radiation at the road surface impacted by traffic & $\mathrm{W} \mathrm{m}^{-2}$ \\
\hline$R_{\mathrm{lu}}$ & Longwave upward radiation & $\mathrm{W} \mathrm{m}^{-2}$ \\
\hline$R_{\mathrm{lu}}^{*}$ & Longwave upward radiation impacted by traffic & $\mathrm{W} \mathrm{m}^{-2}$ \\
\hline$R_{\text {road }}$ & Aerodynamic resistance of dry road & - \\
\hline$R_{\text {road-wat }}$ & Aerodynamic resistance of a wet road & - \\
\hline$R_{\mathrm{sd}}$ & Downward shortwave radiation & $\mathrm{W} \mathrm{m}^{-2}$ \\
\hline$R_{\mathrm{su}}$ & Upward shortwave radiation & $\mathrm{W} \mathrm{m}^{-2}$ \\
\hline RST & Road surface temperature & $\mathrm{K}$ \\
\hline
\end{tabular}




\begin{tabular}{|c|c|c|}
\hline Abbreviations & Synonym & Unit \\
\hline $\mathrm{RST}_{2}$ & Temperature of the second layer of road & K \\
\hline $\mathrm{RST}_{\text {With-traffic }}$ & RST measured by the IR camera (zone subjected to traffic) & K \\
\hline RST Without-traffic $_{\text {W }}$ & RST measured by the IR radiometer (zone not subjected to traffic) & $\mathrm{K}$ \\
\hline $\mathrm{RST}_{\text {measured }}$ & Weighted average of the RST & $\mathrm{K}$ \\
\hline $\mathrm{RST}_{\text {TEB-IC }}$ & RST simulated according the initial configuration of TEB & $\mathrm{K}$ \\
\hline $\mathrm{RST}_{\mathrm{TEB}-\mathrm{A} 1}$ & RST simulated according the first traffic integration approach in TEB & $\mathrm{K}$ \\
\hline $\mathrm{RST}_{\mathrm{TEB}-\mathrm{A} 2}$ & RST simulated according the second traffic integration approach in TEB & $\mathrm{K}$ \\
\hline$R_{\mathrm{V}}$ & Radiative heat flux emitted by vehicle & $\mathrm{W} \mathrm{m}^{-2}$ \\
\hline$S_{\mathrm{a}}$ & Sensible heat flux & $\mathrm{W} \mathrm{m}^{-2}$ \\
\hline$S_{\mathrm{a}}^{*}$ & Sensible heat flux impacted by traffic & $\mathrm{W} \mathrm{m}^{-2}$ \\
\hline$S_{\text {impact }}$ & Traffic area impact & $\mathrm{m}$ \\
\hline$S_{\mathrm{m}}$ & Sensible heat flux from the engine & $\mathrm{W} \mathrm{m}^{-2}$ \\
\hline$S_{\mathrm{t}}$ & Frictional heat flux & $\mathrm{W} \mathrm{m}^{-2}$ \\
\hline$S_{\mathrm{va}}$ & Vehicle sensible heat due to vehicle-induced wind & $\mathrm{W} \mathrm{m}^{-2}$ \\
\hline $\mathrm{SVF}_{\text {road }}$ & Sky view factor of the road & - \\
\hline $\mathrm{SVF}_{\mathrm{walls}}$ & Sky view factor of the walls & - \\
\hline TEB & Town Energy Balance & - \\
\hline$T_{\text {air }}$ & Ambient air temperature at $2 \mathrm{~m}$ height & $\mathrm{K}$ \\
\hline$T_{\text {shield }}$ & Time during which the road surface is covered by the vehicle & s \\
\hline$T_{\text {lowcan }}$ & Temperature of the lower limit layer of urban canyon, assimilated to Tair & $\mathrm{K}$ \\
\hline$t_{\text {time }}$ & Time step & s \\
\hline$T_{\mathrm{t}}$ & Tire temperature & $\mathrm{K}$ \\
\hline$T_{\mathrm{V}}$ & Shielding time due to only one vehicle & s \\
\hline$T_{\mathrm{veh}}$ & Vehicle temperature & $\mathrm{K}$ \\
\hline$T_{\text {veh-inf }}$ & Representative temperature of the lower part of vehicle & K \\
\hline$T_{\text {veh-sup }}$ & Representative temperature of the upper part of vehicle & $\mathrm{K}$ \\
\hline$V_{\text {veh }}$ & Vehicle velocity & $\mathrm{m} \mathrm{s}^{-1}$ \\
\hline$V_{\mathrm{w}}$ & Natural wind velocity & $\mathrm{m} \mathrm{s}^{-1}$ \\
\hline$W_{\text {canyon }}$ & Width of the street canyon & $\mathrm{m}$ \\
\hline$W_{\text {impact }}$ & Width of the traffic impact area & $\mathrm{m}$ \\
\hline$W_{\text {veh }}$ & Width of the vehicle & $\mathrm{m}$ \\
\hline$W_{\text {road }}$ & Width of the road & $\mathrm{m}$ \\
\hline$Y$ & Limit of the turbulence zone beyond the vehicle width & $\mathrm{m}$ \\
\hline$Y^{*}$ & Normalized distance relative to the width of the vehicle & \\
\hline \multirow[t]{2}{*}{$Z_{\text {traffic }}$} & Impact area of traffic & $\%$ \\
\hline & Greek letters & \\
\hline$\alpha_{\mathrm{comb}}$ & Fraction of water vapor that condenses & - \\
\hline$\alpha_{\mathrm{s}}$ & Heat transfer coefficient between atmosphere and road surface & $\mathrm{W} \mathrm{m}^{-2} \mathrm{~K}^{-1}$ \\
\hline$\alpha_{\mathrm{tp}}$ & Heat transfer coefficient between the tire and the road surface & $\mathrm{W} \mathrm{m}^{-2} \mathrm{~K}^{-1}$ \\
\hline$\epsilon_{\text {garden }}$ & Emissivity of the garden & - \\
\hline$\epsilon_{\text {road }}$ & Emissivity of the road & - \\
\hline$\epsilon_{\text {snow }}$ & Emissivity of the snow layer & - \\
\hline$\epsilon_{\mathrm{veh}}$ & Vehicle emissivity & - \\
\hline$\epsilon_{\text {walls }}$ & Emissivity of the walls & - \\
\hline$\lambda_{1}$ & Thermal conductivity of the first road layer & $\mathrm{W} \mathrm{m}^{-1} \mathrm{~K}^{-1}$ \\
\hline$\lambda_{\text {fg }}$ & Latent heat of condensation of water vapor & $\mathrm{J} \mathrm{kg}^{-1}$ \\
\hline$\rho_{\text {air }}$ & Air density & $\mathrm{kg} \mathrm{m}^{-3}$ \\
\hline$\rho_{\text {fuel }}$ & Fuel density & $\mathrm{kg} \mathrm{L}^{-1}$ \\
\hline$(\rho c)_{\text {road }}$ & Volumetric heat capacity & $\mathrm{J} \mathrm{m}^{-3} \mathrm{~K}^{-1}$ \\
\hline$\sigma$ & Stefan-Boltzmann constant & $\mathrm{W} \mathrm{m}^{-2} \mathrm{~K}^{-4}$ \\
\hline$\Delta Z_{\mathrm{s}}$ & Thickness of the first layer of the road surface & $\mathrm{m}$ \\
\hline $1 / f_{\text {road }}$ & Fraction of the road relative to the width of urban canyon & - \\
\hline
\end{tabular}


Acknowledgements. The authors would like to take this opportunity to thank IFSTTAR and Météo France for their financial support, and Mathieu Moutton and Stéphane Ludwig for performing all the measurements.

Edited by: T. Poulet

\section{References}

Borgen, J., Gustavsson, T., and Londquist, S.: A description of a local climatological model used to predict temperature variation along stretches of road, Meteorol. Mag., 121, 157-165, 1992.

Bouilloud, L. and Martin, E.: A coupled model to simulate snow behavior on roads, J. Appl. Meteorol. Clim., 45, 500-516, doi:10.1175/JAM2350.1, 2006.

Bouilloud, L., Martin, E., Habets, F., Boone, A., Moigne, P. L., Livet, J., Marchetti, M., Foidart, A., Franchistéguy, L., Morel, S., Noilhan, J., and Pettré, P.: Road surface condition forecasting in france, J. Appl. Meteorol. Clim., 48, 2513-2527, 2010.

Brown, B. G. and Murphy, A. H.: Improving forecasting performance by combining forecasts: the example of road surface temperature forecasts, Meteor. Appl., 3, 257-265, 1996.

Browne, A. L., Wicker, D., and Segalman, D.: A general model for power loss in pneumatic tires, GM Research Laboratories, Engineering Mechanics Department, GMR-4005, 1980.

Chapman, L., Thornes, J. E., and Bradley, A. V.: Modeling of road surface temperatures from a geographical parameter database. Part 1, Statistical, Meteor. Appl., 8, 409-419, 2001.

Colombert, M.: Contribution to the analysis of the various means to take into account urban climate in urban planning, $\mathrm{PhD}$ thesis, Engineering Science, University of Paris-Est, France, 2008.

Crevier, L. P. and Delage, Y.: METRo: A new model for roadcondition forecasting in Canada, J. Appl. Meteorol., 40, 20262037, 2001.

Farmer, S. F. and Tonkinson, P. J.: Road surface temperature model verification using input data from airfields, roadside sites and the meso-scale model, UK Meteorological Office, Exeter, UK, 1989.

Fujimoto, A., Watanabe, H., and Fukuhara, T.: Effects of tire frictional heat on snow covered road surface, in: Proceedings of the 13th SIRWEC Conference, 6 pp., Torino, Italy, available at: http://www.sirwec.org/Papers/torino/17.pdf (last access: 7 February 2016), 2006.

Fujimoto, A., Watanabe, H., and Fukuhara, T.: Modeling of vehicle heats and its influence on surface temperature of dry road, J. Jpn. Soc. Civil. Eng., 63, 202-2013, 2007.

Fujimoto, A., Watanabe, H., and Fukuhara, T.: Effects of vehicle heat on road surface temperature of dry condition, in: Proceedings of the 14th Standing International Road Weather Conference, Standing International Road Weather Commission, ID05, Prague, Czech Republic, available at: http://www.sirwec.org/ Papers/prague/5.pdf (last access: 7 February 2016), 2008.

Fujimoto, A., Saida, A., Fukuhara, T., and Futagami, T.: Heat transfer analysis on road surface temperature near a traffic light, in: Proceedings of the 17th ITS World Congress, T_AP01138, Busan, South Korea, Intelligent Transportation Society, 2010.

Fujimoto, A., Watanabe, H., and Fukuhara, T.: A New Approach to Modeling Vehicle-Induced Heat and Its Thermal Effects on Road
Surface Temperature, J. Appl. Meteorol. Clim., 51, 1980-1993, 2012.

Guibet, J. C.: Carburants liquides, in: Techniques de l'ingénieur, BE 8545, Techniques de l'ingénieur, 1998.

Gustavsson, T. and Bogren, J.: Infrared thermography in applied road climatological studies, Int. J. Remote Sens., 19, 1311-1328, 1991.

Gustavsson, T., Bogren, J., and Greeb, C.: Road climate in cities: a study of Stockholm area, south-east Sweden, Meteorol. Appl., 8, 481-490, 2001.

Ichinose, T., Shimodozono, K., and Hanaki, K.: Impact of anthropogenic heat on urban climate in Tokyo, Atmos. Environ., 33, 3897-3909, 1999.

Ishikawa, N., Narita, H., and Kajiya, H.: Contribution of heat from traffic vehicle to snow melting on roads, Transp. Res. Rec., 1672, 28-33, 1999.

Jacobs, W. and Raatz, W. E.: Forecasting road surface temperature for specific site characteristics using an energy balance model, in: Proceeding of the 8th SIRWEC Conference, 17-19 April, 10 pp., Birmingham, UK, 1996.

Khalifa, A., Marchetti, M., and Buès, M.: Appreciation of the traffic effects on the RST by infrared thermography, in: Proceeding of the SPIE 9223, Remote Sensing System Engineering V, 2014.

Klysik, K.: Spatial and seasonal distribution of anthropogenic heat emissions in Lodz Poland, Atmos. Environ., 30, 3397-3404, 1996.

Lemonsu, A., Bélair, S., Mailhot, J., Benjamin, M., Morneau, G., Harvey, B., Chagnon, F., Jean, M., and Voogt, J.: Overview and First Results of the Montreal Urban Snow Experiment 2005, J. Appl. Meteorol. Clim., 47, 59-75, 2008.

Lemonsu, A., Bélair, S., Mailhot, J., and Leroyer, S.: Evaluation of the Town Energy Balance Model in Cold and Snowy Conditions during the Montreal Urban Snow Experiment 2005, J. Appl. Meteorol. Clim., 49, 346-362, 2010.

Lemonsu, A., Masson, V., Shashua-Bar, L., Erell, E., and Pearlmutter, D.: Inclusion of vegetation in the Town Energy Balance model for modelling urban green areas, Geosci. Model Dev., 5, 1377-1393, doi:10.5194/gmd-5-1377-2012, 2012.

Leroyer, S., Mailhot, J., Bélair, S., Lemonsu, A., and Strachan, I. B.: Modeling the Surface Energy Budget during the Thawing Period of the 2006 Montreal Urban Snow Experiment, J. Appl. Meteorol. Clim., 49, 68-84, 2010.

Masson, V.: A physically-based scheme for the urban energy budget in atmospheric models, Bound.-Lay. Meteorol., 94, 357-397, 2000.

Masson, V., Le Moigne, P., Martin, E., Faroux, S., Alias, A., Alkama, R., Belamari, S., Barbu, A., Boone, A., Bouyssel, F., Brousseau, P., Brun, E., Calvet, J.-C., Carrer, D., Decharme, B., Delire, C., Donier, S., Essaouini, K., Gibelin, A.-L., Giordani, H., Habets, F., Jidane, M., Kerdraon, G., Kourzeneva, E., Lafaysse, M., Lafont, S., Lebeaupin Brossier, C., Lemonsu, A., Mahfouf, J.-F., Marguinaud, P., Mokhtari, M., Morin, S., Pigeon, G., Salgado, R., Seity, Y., Taillefer, F., Tanguy, G., Tulet, P., Vincendon, B., Vionnet, V., and Voldoire, A.: The SURFEXv7.2 land and ocean surface platform for coupled or offline simulation of earth surface variables and fluxes, Geosci. Model Dev., 6, 929-960, doi:10.5194/gmd-6-929-2013, 2013. 
Parmenter, B. S. and Thornes, J. E.: The use of a computer model to predict the formation of ice on road surfaces, Transport and Road Research Laboratory, Research Report, 71, 1-19, 1986.

Paumier, J. and Arnal, M.: Expérimentation Préviroute sur l'autoroute A75 dans le Cantal, Revue générale des routes et des aérodromes, 758, 44-51, 1998.

Pigeon, G., Legain, D., Durand, P., and Masson, V.: Anthropogenic heat release in an old European agglomeration (Toulouse, France), Int. J. Climatol., 27, 1969-1981, 2007.

Pigeon, G., Moscicki, M. A., Voogt, J. A., and Masson, V.: Simulation of fall and winter surface energy balance over a dense urban area using the TEB scheme, Meteorol. Atmos. Phys., 102, 159-171, 2008.

Prusa, J. M., Segal, M., Temeyer, B. R., Gallus, W. A., and Takle, E. S.: Conceptual and scaling evaluation of vehicle traffic thermal effects on snow/ice-covered roads, J. Appl. Meteorol., 41, 12251240, 2002.

Raatz, W. and Niebrügge, L.: Road weather forecats for a winter road maintenance information center, in: Proc. 11th SIRWEC, Sapporo, Japan, 2002.

Rayer, P. J.: The Meteorological Office forecast road surface temperature model, Meteor Mag., 116, 180-191, 1987.

Saas, B.: A numerical model for prediction of road surface temperature and ice, J. Appl. Meteor., 31, 1499-1506, 1992.

Sailor, D. J. and Lu, L.: A top-down methodology for developing diurnal and seasonal anthropogenic heating profiles for urban areas, Atmos. Environ., 38, 2737-2748, 2737-2748, 2004.

Sass, B. H.: A numerical forecasting system for the prediction of slippery roads, J. Appl. Meteorol., 36, 801-817, 1997.
Sato, T., Kosugi, K., Abe, O., Mochizuki, S., and Koseki, S.: Wind and air temperature distribution in the wake of a running vehicle, in: Proceeding of the 12th SIRWEC Conference, 7 pp., Bingen, Germany, available at: http://www.sirwec.org/Papers/bingen/6. pdf (last access: 7 February 2016), 2004.

Shao, J. and Lister, P. J.: The prediction of road surface state and simulation of the shading effect, Bound.-Lay. Meteorol., 73, 411-419, 1995.

Shao, J. and Lister, P. J.: An automated now casting model of road surface temperature and state for winter road maintenance, J. Appl. Meteorol., 35, 1352-1361, 1996.

Sundvor, B. R. D. I.: NORTRIP Model development and documentation: Non-exhaust Road Trafic Induced Particle, scientific report, Norwegian Institute for Air Research, 2012.

Surgue, J. G., Thornes, J. E., and Osborne, R. D.: Thermal mapping of road surface temperatures, Phys. Technol., 13, 212-213, 1983.

Takahashi, N., Asano, M., and Ishikawa, M.: Developing a method to predict road surface icing conditions applying a heat balance method, in: Proceeding of Cold Region Technology Conference, 201-208, 2005.

Takle, E. S.: Bridge and roadway frost occurrence and prediction by use of an expert system, J. Appl. Meteor., 29, 727-734, 1990. 